\title{
Assessment of the Land Surface and Boundary Layer Models in Two Operational Versions of the NCEP Eta Model Using FIFE Data
}

\author{
ALAN K. BeTTS \\ Pittsford, Vermont
}

\author{
Fei Chen, Kenneth E. Mitchell, and Zaviša I. Janjić \\ NCEP/EMC, Washington, DC
}

(Manuscript received 23 July 1996, in final form 28 March 1997)

\begin{abstract}
Data from the 1987 summer FIFE experiment for four pairs of days are compared with corresponding 48-h forecasts from two different versions of the Eta Model, both initialized from the NCEP-NCAR (National Centers for Environmental Prediction-National Center for Atmospheric Research) global reanalysis. One used the late 1995 operational Eta Model physics, the second, with a new soil and land surface scheme and revisions to the surface layer and boundary layer schemes, used the physics package that became operational on 31 January 1996. Improvements in the land surface parameterization and its interaction with the atmosphere are one key to improved summer precipitation forecasts. The new soil thermal model is an improvement over the earlier slab soil model, although the new skin temperature generally now has too large a diurnal cycle (whereas the old surface temperature had too small a diurnal cycle) and is more sensitive to net radiation errors. The nighttime temperature minima are often too low, because of a model underestimate of the downwelling radiation, despite improvements in the coupling of the surface and boundary layer at night. The daytime incoming solar radiation has a substantial high bias in both models, because of some coding errors (which have now been corrected), insufficient atmospheric shortwave absorption, and underestimates of cloud.

The authors explore evaporation before and after a midsummer heavy rain event with the two models. The late 1995 operational model uses a soil moisture bucket physics, with a specified annual-mean fixed field soil moisture climatology, so the surface evaporation responds primarily to the atmospheric forcing. While the surface fluxes in the new model show this strong rain event more dramatically, because its soil moisture comes from the global reanalysis rather than climatology, there remain problems with soil moisture initialization. It appears that a fully continuous Eta data assimilation system (which is under development), likely with more than two soil layers and assimilation of observed hourly precipitation, will be needed to get an adequate soil moisture initialization. Evaporation in the new two-layer soil model falls too much from forecast day 1 to day 2, as the first shallow 10-cm layer dries out (as it also does in the 1995 model with the bucket physics). This appears to be related to the specified low vegetation fraction and the bare soil evaporation model. Although the new boundary layer scheme is better coupled to the surface at night, both versions underestimate entrainment at the top of the mixed layer. The improvement in the surface evaporation resulting from using a climatological green vegetation fraction (derived from satellite data) and a revised bare soil evaporation formulation are shown. These changes were incorporated in a model physics revision in February 1997. An encouraging result from one case study, when it rained in the model, shows that the interaction between the surface, boundary layer, and convection schemes during precipitation is satisfactory, although the model underestimates the impact of cloud cover on the incoming solar radiation.
\end{abstract}

\section{Introduction}

The implementation plan (Leese 1993) for the Global Energy and Water Cycle Experiment Continental-Scale International Project (GCIP) envisaged an archive of model surface and upper-air fields from the Environmental Modeling Center mesoscale forecast system: the so-called Eta Model, named after its step mountain co-

Corresponding author address: Dr. Alan K. Betts, RR 3, Box 3125 , Pittsford, VT 05763.

E-mail: akbetts@aol.com ordinate system (Mesinger et al. 1988; Janjić 1990). The main GCIP archive collection from the Eta Model began on 1 November 1995, and in the two preceding summers, test datasets were archived (Leese 1994) from 16 July to 31 August 1994 as part of the GCIP Integrated Systems Test (GIST), and from the 1 April to 31 October 1995 for the enhanced special observing period (ESOP95). One of the purposes of GCIP is to accelerate the development of model improvements by comparison against field data.

This paper uses the FIFE-1987 (First ISLSCP Field Experiment) data to explore some characteristics of the 
new surface physics of two versions of the Eta Model physics: the operational October 1995 model, and a new model physics, which became the operational Eta Model on 31 January 1996. We shall refer to these two operational model physics versions as OCT95 and FEB96. Both these model versions became operational at $48-\mathrm{km}$ resolution, although the comparisons we use here were run at $80-\mathrm{km}$ resolution. We do not believe our results at the FIFE site depend on this difference in resolution. There were several versions of the Eta Model over the 1994-96 period. The operational model change in October 1995 was the addition of explicit cloud water prediction in the large-scale precipitation-condensation scheme. At the same time, the operational model resolution dropped from 80 to $48 \mathrm{~km}$. The ESOP-95 summer archive was generated using this same model version, with explicit cloud microphysics, running earlier in parallel at $48-\mathrm{km}$ resolution. The GIST-94 archive, however (which was also generated from a parallel run at $48 \mathrm{~km}$ ), used the same model, prior to the inclusion of the explicit cloud water scheme.

The intent of this paper is to provide some documentation of these two models' performance at the land surface (which will be helpful for users of the GCIP data archives, as they were used for the ESOP-95 and the current ongoing GCIP archive, respectively), as well as provide guidance for the development of the next model cycle. We use the well-documented FIFE data from 1987 for running test cases, because this dataset has already proved of great value for studying global model near-surface parameterizations (Betts et al. 1993; Betts et al. 1996a).

This investigation focuses on only a few areas of the Eta Model and its land surface interaction, where the correction of errors led to significant improvements. A full analysis and forecast system is complex, and many components are not explored here, such as errors in the forecast 3D atmospheric fields or (for the most part) in the cloud fields. We did not explore the impact of the specification of soil parameters on the model skill. Some other important issues, such as the limited vertical resolution of the soil model and the need to specify soil moisture from a global model, as well as apparent errors in longwave radiation and boundary layer top entrainment will be addressed in future versions of the Eta Model. Here we simply identify them as possible contributors to model error.

\section{Comparison methodology}

We discuss the two model versions, the comparison methodology and the FIFE data that we used.

\section{a. Eta Model physics}

We use two versions of the Eta Model, which differ only in their soil, near-surface, and boundary layer (BL) physical parameterizations. The OCT95 model is doc- umented in Janjić (1990, 1994), Lobocki (1993), Mesinger (1993), and Gerrity et al. (1994). It uses a bucket model for the soil hydrology. The essential differences between the FEB96 model and the OCT95 model are outlined in appendix B. The later FEB96 model has a new soil and land surface parameterization [based on the Oregon State University (OSU) scheme of Pan and Mahrt (1987) as outlined in Janjić (1996b,c) and Chen et al. (1996)], a different surface layer model discussed in Chen et al. (1997) [using functions from Paulson (1970), a viscous sublayer formulation by Zilitinkovich (1995), and a free convection correction by Beljaars (1995)], and revisions to the BL scheme, discussed in Janjić (1996a). Both models have two soil layers (10 and $190 \mathrm{~cm}$ thick), because the regional model soil moisture and temperature is initialized from the global model, which has this layer structure. Both models use the soil model of Mahrt and Pan (1984). The OCT95 model has a single soil type, but in the FEB96 model, a spatial distribution of soil type and soil properties was introduced (see appendix B). We did not study the sensitivity to the soil specification.

Several methods have been used to test and improve physical parameterizations in large-scale models. For the Eta Model, improvements in precipitation skill scores, averaged over the United States, have been used as test criteria for many years. Offline single column methods have been used to test different components of land surface models. Chen et al. (1996a) used the FIFE site-average surface radiation and meteorological data to force single column versions of four land-surface schemes, which were integrated for the FIFE summer period from 22 May to 16 October 1987. One scheme used the bucket model of Manabe (1969), with the modification discussed in Pan (1990), which is similar to the scheme used in the OCT95 Eta Model, although OCT95 did not use the Pan (1990) calculation of potential evaporation. One of the other three schemes used an extension of the vegetation-soil model of Pan and Mahrt (1987); this is included in the second version (FEB96) of the Eta Model tested here. Chen et al. (1996a) concluded from these offline comparisons with FIFE flux data that the Pan and Mahrt model was superior to the bucket model in its ability to represent both the diurnal and seasonal cycles, and so it was subsequently incorporated in full versions of the Eta Model under development.

Here we pursue a third mode of model testing by comparing 48-h forecasts from two different versions of the model for the grid point near the FIFE site (see section $2 b$ ) with the observed near-surface data and fluxes. This tests the ability of the fully interactive model (with parameterizations for soil hydrology and temperature, vegetation, surface transfer, boundary layer, convection, radiation, and clouds) to reproduce the observed land surface diurnal cycle. One component of this fully interactive system is not yet complete: a continuous data assimilation with the Eta Model. Nonethe- 
less, these comparisons provide useful information on the performance and interaction of the physical parameterizations in the Eta Model, as it undergoes further development.

There are some differences between the Global Data Assimilation System (GDAS) for the 2 years: in 1994 the soil hydrology used the bucket model of Pan (1990), while in 1995 the two-layer soil model of Pan and Mahrt (1987) was used. During the summer of 1994 and 1995 the Eta Model was initialized from the GDAS using a 12-h Eta data assimilation cycle. Analyses using this same 1995 version of the global medium-range forecast model (at a lower T-62 spectral resolution) are available also for 1987, since this global model was used for the reanalysis project (Kalnay et al. 1996). In this paper, we use 48-h Eta forecasts using the OCT95 and FEB96 model physics (at 80-km horizontal resolution), initialized from the global reanalysis (without a 12-h EDAS analysis cycle) for four selected days in 1987: 5 June, 8 July, 9 August, and 15 August. We compare the hourly time series of surface and BL model variables in these forecasts with corresponding time series from the FIFE surface data (available every $30 \mathrm{~min}$ ) and sounding data (which were typically available every 90 min on sunny days).

A second important issue in the fully interactive land surface problem, which has not yet been fully resolved in any large-scale model, is how to properly initialize soil moisture. In this study, the initial soil moisture for each 48-h forecast is different for the OCT95 and FEB96 physics. The OCT95 model used an annual-mean fixed field climatology for the bucket soil moisture. The FEB96 model soil moisture comes with slight modification (see appendix B) from the soil moisture predicted by the global reanalysis. We will later discuss briefly the problem of soil moisture initialization, as it limits our ability to assess the new soil-vegetation-evaporation model.

The two previous studies discuss some of the difficulties in using the FIFE site-averaged data (a $15 \mathrm{~km}$ $\times 15 \mathrm{~km}$ domain) to validate large-scale models (Betts et al. 1993; Betts et al. 1996a). Given the heterogeneities of the land surface, the representivity of data from a 15 $\mathrm{km} \times 15 \mathrm{~km}$ domain for (in our case here) an $80 \mathrm{~km}$ $\times 80 \mathrm{~km}$ grid square in a mesoscale model can always be questioned. The FIFE sonde data that we use here, like all sonde data, represent only a brief snapshot through the BL every $90 \mathrm{~min}$, but we have consistent sequences of soundings on most days, showing the diurnal evolution of the BL. Over a dense network like the United States, it is reasonable to expect that the synoptic-scale fields are resolved by the observing network and therefore represented in the analysis. However, the land surface diurnal cycle in a 48 -h forecast is largely a product of the model soil, surface, and BL and perhaps convection parameterizations, as well as the model calculation of the surface net radiation budget, which is itself a function of the model cloud fields. The ability of a model to represent the observed diurnal cycle of the surface fields is a useful diagnostic, which gives insight into the interaction of the model parameterizations. One cannot expect exact detailed agreement, but we will show cases where the model physics is clearly unrealistic and needs improvement. Comparisons at one point can be sufficient to show where model parameterizations are likely to be in error, simply because the model fields are systematically inconsistent with the corresponding observations over a number of days. On the other hand, reasonable agreement with data at one site does not mean the model parameterizations are perfect. Comparisons with data from different sites are essential to see whether the model physics can represent well both grassland and boreal forest, or the arid regions of the U.S. Southwest, as well as regions where rainfall is plentiful. So this analysis, which compares forecasts for only four pairs of days from two versions of the Eta with the corresponding FIFE data, is only one step in the long task of improving the physical parameterizations in a forecast model. In fact, this study showed up several errors and problems in the model physics.

\section{b. FIFE data}

Both the raw data and most of our site-averaged time series are available on CD-ROM (Strebel et al. 1994). The details of the production of our FIFE-site average data are in the appendix of Betts et al. (1993) and in Betts and Ball (1994). The editing of the raw data involved both the use of simple range filters and extensive manual editing of bad data. There were data from as many as ten surface portable automated meteorological stations in each 30-min average. These are labeled "AMS" on the figures. We also averaged the surface flux data (labeled "FLUX" data on figures) from 17 selected surface sites, which took measurements during the four intensive field campaigns. The upper-air data we use was from visually tracked radiosondes (Sugita and Brutsaert 1990a,b), which were launched roughly every $90 \mathrm{~min}$ on almost all sunny days. This data is available also on Strebel et al. (1994) both as raw data (resolution a few millibars) and interpolated to standard 5 -mb levels. The vertical resolution of the sonde data is much finer than that of the Eta Model.

\section{Comparison of 5-6 June forecasts from two eta models and the FIFE observations}

Our first comparisons are 48-h forecasts from 0000 UTC 5 June, initialized from the National Centers for Environmental Prediction-National Center for Atmospheric Research (NCEP-NCAR) global reanalysis (Kalnay et al. 1996), including soil moisture and temperature. We will compare data in turn with the model near-surface fluxes, surface variables, and BL evolution. Soils in both FIFE and the reanalysis were wet in early June, although the two preceding days had been rain 


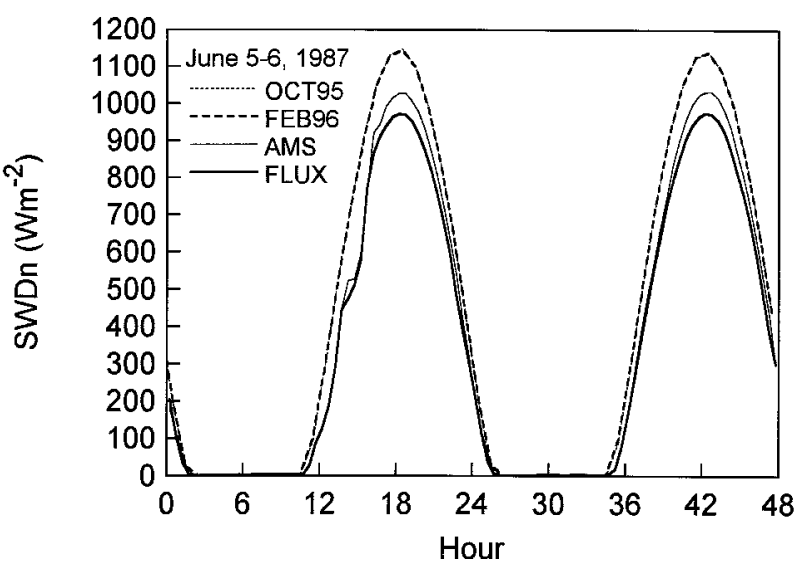

FIG. 1. Comparison of incoming solar flux (SWDn) for FIFE-site averages (AMS and FLUX data) for 5-6 June 1987 with 48-h forecast of the Eta OCT95 and FEB96 models starting from 0000 UTC 5 June.

free in the reanalysis. These two days are similar undisturbed days with little cloud cover or synoptic-scale advection.

\section{a. Surface fluxes}

Figure 1 shows the comparison of the incoming solar radiation for these two sunny days, 5 and 6 June 1987 (the time axis starts at 0000 UTC 5 June). Both versions of the model have the same incoming flux, peaking near $1140 \mathrm{~W} \mathrm{~m}^{-2}$. For the data we show two curves for the AMS- and FLUX-site averages. The lower FLUX-site average is probably the better calibrated data (Betts et al. 1993). The incoming solar flux at noon in the Eta Model is about $10 \%-15 \%$ too high $\left(100-150 \mathrm{~W} \mathrm{~m}^{-2}\right)$. On these days the standard deviation for the stations in the FLUX average is about $25 \mathrm{~W} \mathrm{~m}^{-2}$ at local noon. The model albedo near noon is $19.5 \%$, a little higher (not shown) than the FIFE grassland $(\sim 18 \%)$.

Other forecast models (e.g. Betts et al. 1993; Betts et al. 1996a) also appear to have a high incoming solar radiation bias, presumably because the model atmosphere is too transparent. The high bias in the Eta Model was, however, even larger, so the shortwave radiation code was reexamined and two errors were found. The earth's orbit had been treated as circular, rather than elliptical with aphelion in summer: this introduces a $3.3 \%$ high bias in the northern summer. A coding error had also turned off the ozone absorption in the atmosphere: this accounted for an additional $2 \%$ high bias. These coding errors account for perhaps half the high bias, and they were corrected in the next operational version of the model. In addition, the current radiation code does not include aerosol absorption, and it may have insufficient absorption in the water vapor continuum, but these possible sources of bias are still being explored.

Not surprisingly, the net radiation $R_{n}$ in the model in Fig. 2 is also significantly higher than that observed.

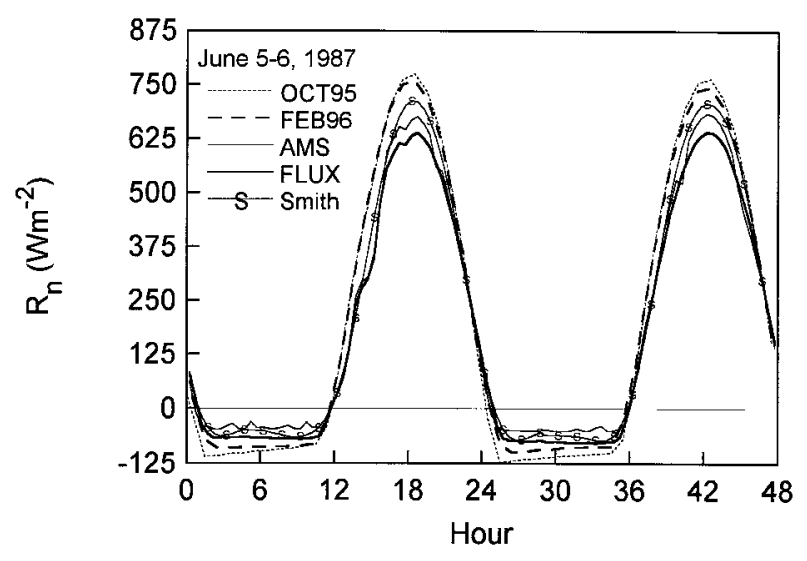

FIG. 2. As in Fig. 1 but for net radiation $R_{n}$, with Smith et al. (1992a) average added.

For the FIFE data, the heavy line corresponds to the FLUX average (on these days including about 15 sites). As a cautionary note on the problems with real data, we also show a two-station average (as a light line with embedded symbol S) from two sites (Smith et al. 1992a) that measured separately all four radiation flux components with calibrated radiometers. Although the net radiometers at the FLUX sites were also calibrated, the FIFE investigators never fully resolved their $R_{n}$ calibration differences (Smith et al. 1992a; Smith et al. 1992b), so the difference between these two datasets is a measure of the calibration uncertainty of measured $R_{n}$. Nonetheless, it appears that the model incoming net radiation is too large in the daytime, and its outgoing net radiation is too large at night. In the FEB96 model, which has a skin temperature with no thermal inertia, we shall see later (section $3 b$ ) that this produces too large a diurnal amplitude in the surface temperature.

Figure 3 compares downwelling longwave (LW) fluxes. There are some significant differences at night; the model has a smaller downwelling LW flux than the FIFE FLUX data (this data is only a two-station average from

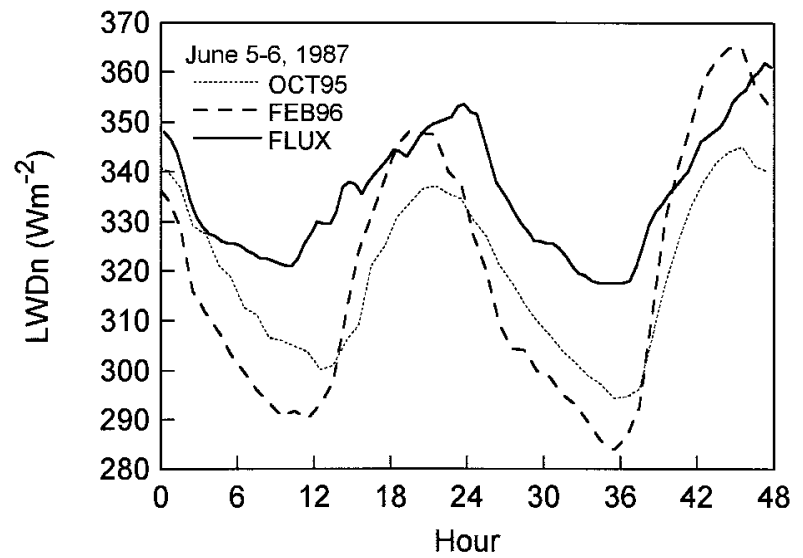

FIG. 3. As in Fig. 1 but for LW down flux at surface; data is FLUX-site average. 


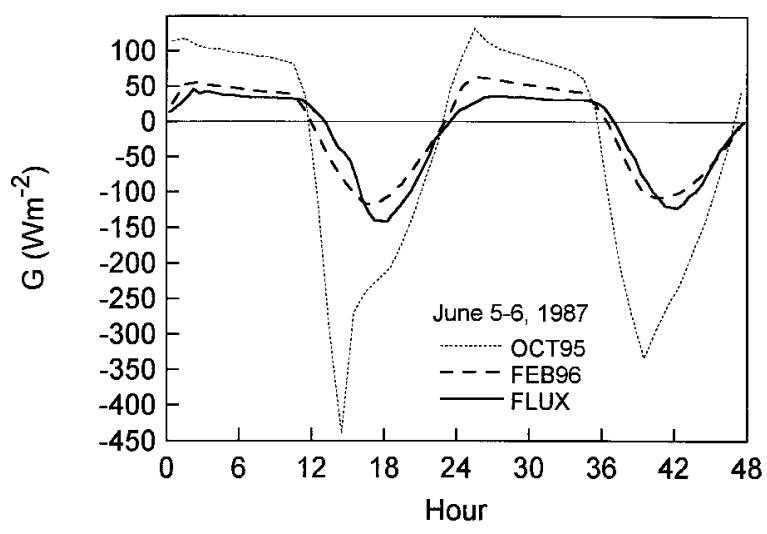

FIG. 4. As in Fig. 3 but for ground heat flux.

Smith). Before sunrise, the downwelling LW flux (LWDn) in the FEB96 model is about $35 \mathrm{~W} \mathrm{~m}^{-2}$ less than observed. Because the skin temperature is calculated from a surface energy balance, this low incoming LW at night is in part the cause of the low FEB96 $T_{\text {surf }}$ minimum at sunrise, which we shall see later (section $3 \mathrm{~b}$ ). The OCT95 model has a larger nighttime value (although it is still $20 \mathrm{~W} \mathrm{~m}^{-2}$ low at sunrise), probably because it has a warmer BL (see section 3c). The daytime peak in downwelling LW flux is a few hours later in the data than the model; we do not know the cause of this.

Figure 4 compares the ground heat flux $G$ for the two models and the FIFE data. The improvement in the ground flux both day and night with the new soil model (FEB96) is very apparent. The ground flux in the OCT95 model with the slab soil model is much too large in the daytime. There is a large morning peak, as the $10-\mathrm{cm}$ soil layer must heat up before the surface $T$ is high enough to transfer energy to the atmosphere. Betts et al. (1993) noted the same behavior in the 1992 European Centre model, which at that time also used a slab soil thermal model. When the OCT95 model was originally formulated, the 10-cm depth of the first soil layer was chosen to have a thermal capacity comparable to that of the first model layer (Janjić 1990), which was then $300 \mathrm{~m}$. However, as the vertical resolution of the atmospheric model has been increased, the thickness of the first soil layer has not been correspondingly reduced, and clearly $10 \mathrm{~cm}$ is too thick a soil layer to give a realistic surface interaction. The FEB96 model avoids this issue by having a separate skin temperature, but this skin temperature is instead very sensitive to the surface radiation balance (see section $3 b$ ).

Figure 5 shows the latent heat (LH) flux comparison. The observed peak is around $400 \mathrm{~W} \mathrm{~m}^{-2}$ on both days; it is early June and the soil moisture is high. For the Eta Model, FEB96 has a higher LH flux than the OCT95 model (less energy goes into the ground, Fig. 4), but the trend for both is a marked decrease in evaporation on the second forecast day. In OCT95, the bucket ef-

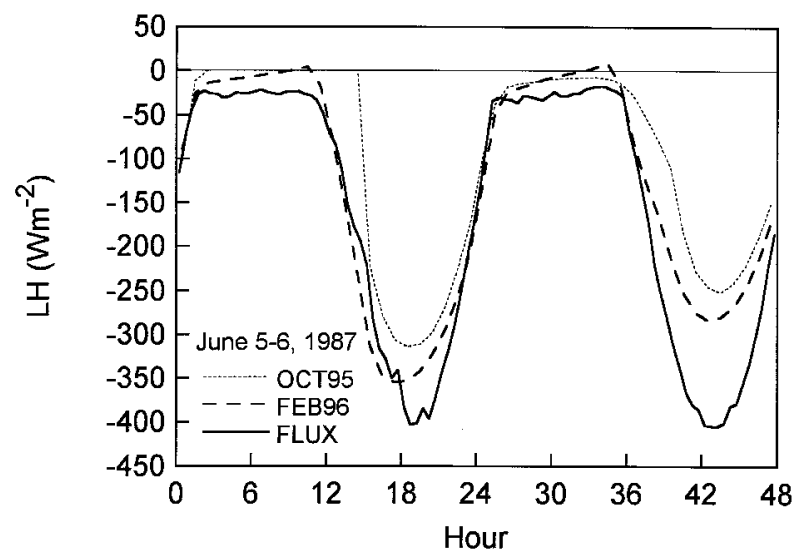

FIG. 5. As in Fig. 3 but for LH flux.

fectively only contains enough water for a few days evaporation (about $11 \mathrm{~mm}$ ), because it has a specified low-moisture availability parameter (see appendix B), so its behavior is understandable and very similar in all our simulations. For the FEB96 model, it appears that with no rain, the model evaporation falls quickly as the first soil layer dries. This was unexpected, so we explored the reason carefully. Evaporation in the FEB96 model (when the canopy is dry) is a sum of evapotranspiration, which depends on vegetation fraction, and evaporation from the bare soil. The Eta Model specified vegetation fraction at this FIFE grid point in June is only 0.54 , too low for this grassland site. The bare soil evaporation (from the unvegetated $46 \%$ of the grid square) falls rapidly as soil moisture declines, because it is calculated by the so-called threshold method from Mahrt and Pan (1984). This is discussed further in section 6 .

Figure 6 shows the corresponding surface heat $(\mathrm{SH})$ flux comparison. The observed SH flux is low in spring $\left(100-120 \mathrm{~W} \mathrm{~m}^{-2}\right.$ peak), while in the FEB96 model, the SH flux is much too high and increases from 300 to 360 $\mathrm{W} \mathrm{m}^{-2}$ on the second day, presumably as the first soil layer dries and direct evaporation falls. The net radiation

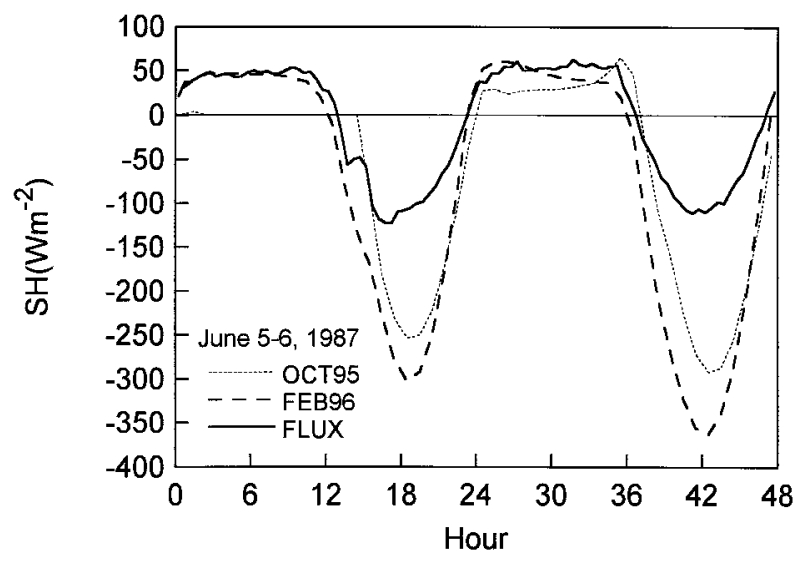

FIG. 6. As in Fig. 3 but for SH flux. 


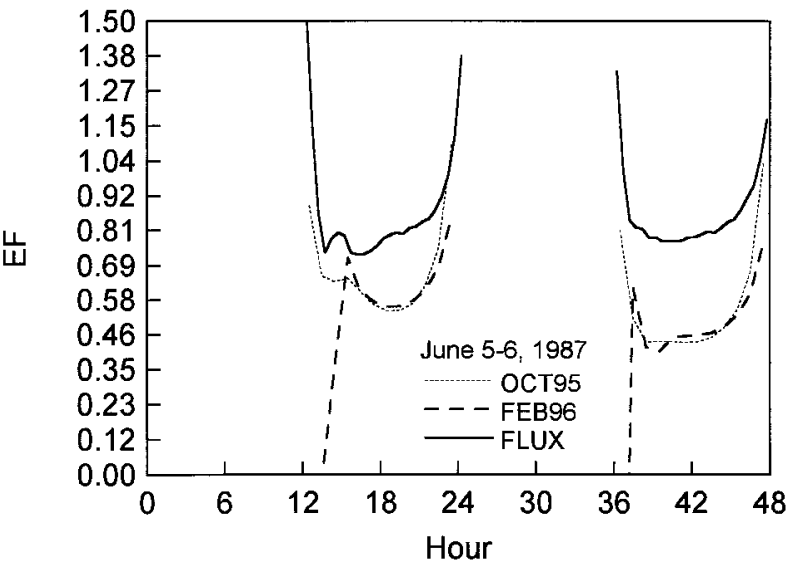

FIG. 7. As in Fig. 3 but for daytime surface evaporative fraction.

has a high bias (Fig. 2), because of the incoming solar radiation bias (Fig. 1), but clearly the model evaporative fraction is also too low (see below). We shall see later that this high SH flux produces too warm a BL. The OCT95 model SH flux has a similar behavior, as the water level in its bucket falls, although the flux is smaller, because of the large erroneous ground flux in that model version (Fig. 4). The OCT95 model shows a phase lag after sunrise in both SH and LH of about 2 $\mathrm{h}$, as the energy goes to warm the first ground layer (the downward spike in Fig. 4). The OCT95 model also has zero heat flux on the first night, when the model inversion is strong (see Fig. 13 below).

Figure 7 shows the corresponding daytime evaporative fraction $[\mathrm{EF}=\mathrm{LH} /(\mathrm{SH}+\mathrm{LH})]$. This shows the data with $\mathrm{EF} \sim 0.8$, a typical value for the FIFE region for that spring and summer, except for prolonged periods of no rain (Smith et al. 1992a; Smith et al. 1992b). In both versions of the Eta Model, EF at noon is too low and, furthermore, EF falls from 0.54 on the first day to 0.44 on the second: such low values were found in the FIFE region that summer only at the end of July, after 2 weeks with no rain. Evaporation falls too quickly in both versions of the model in the absence of rain, in a matter of days rather than weeks, for the reasons discussed above.

\section{b. Diurnal cycle of surface thermodynamics}

With these surface flux comparisons in mind, we now look at the 2-m temperature and moisture, which are important archive products for GCIP. Values are not predicted by the Eta Model at this level but diagnosed from the values predicted for the surface and the lowest model level, which over the FIFE site in Kansas is about $70 \mathrm{~m}$ above the surface.

Figure 8 shows the diurnal cycle of 2-m temperature $\left(T_{2}\right)$ for the OCT95 model and the FEB96 versions of the Eta Model, and the FIFE data (solid) for the corresponding 2 days, 5-6 June. The OCT95 model (dot-

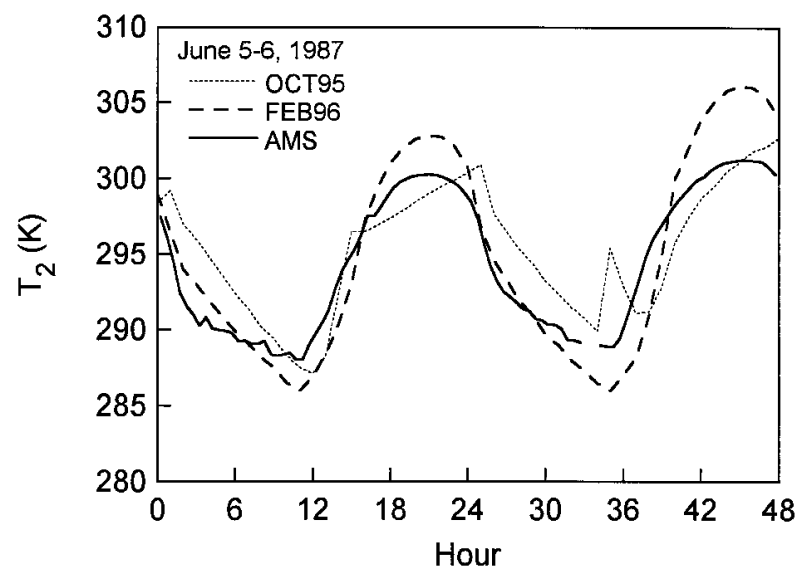

FIG. 8. Comparison of 2-m temperature for FIFE-site average for 5-6 June 1987 with 48-h forecast of the Eta OCT95 and FEB96 models starting from 0000 UTC 5 June.

ted) has a distinct unrealistic daytime structure and shows noise at $35 \mathrm{~h}$ at night. Although the variables predicted at the lowest model level were computed correctly in the OCT95 model, there was an error in the scheme that diagnosed the 2-m variables (see appendix A). This problem was corrected in the FEB96 model. The FEB96 model has a smooth diurnal cycle of $T_{2}$, although the daytime maximum is about $4 \mathrm{~K}$ too large, because of the large sensible heat flux (Figure 6).

Figure 9 shows the surface temperature $T_{\mathrm{afc}}$ in the model compared with the data. The FIFE surface temperature was measured radiometrically. The OCT95 model is closer in diurnal amplitude to the data but cools more slowly at night, as it uses a slab thermal model for the first $10 \mathrm{~cm}$ of soil in the surface energy budget. The temperature of this first soil layer is also the surface temperature. We have seen (Figs. 4-6) that the thermal inertia of this thick slab soil model (in OCT95) introduces significant errors into the ground heat flux, and

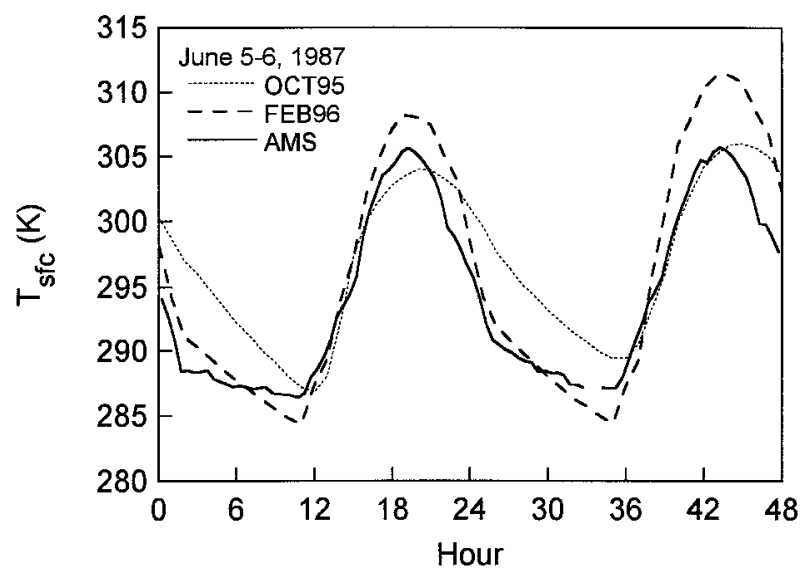

FIG. 9. As in Fig. 8 but for surface temperature. FIFE data is a radiometric temperature; for OCT95 model it is the temperature of the first $10-\mathrm{cm}$ soil layer, and for FEB96 it is a skin temperature. 
(a)

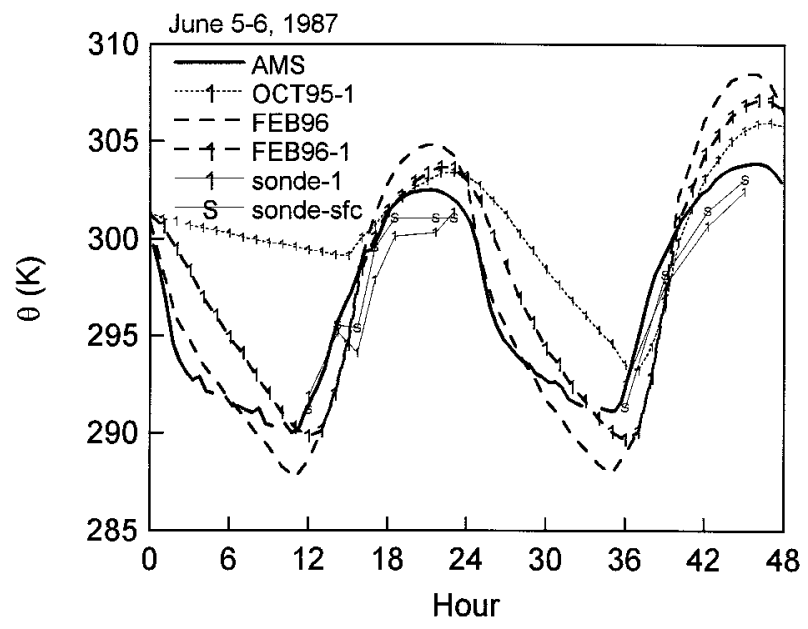

(b)

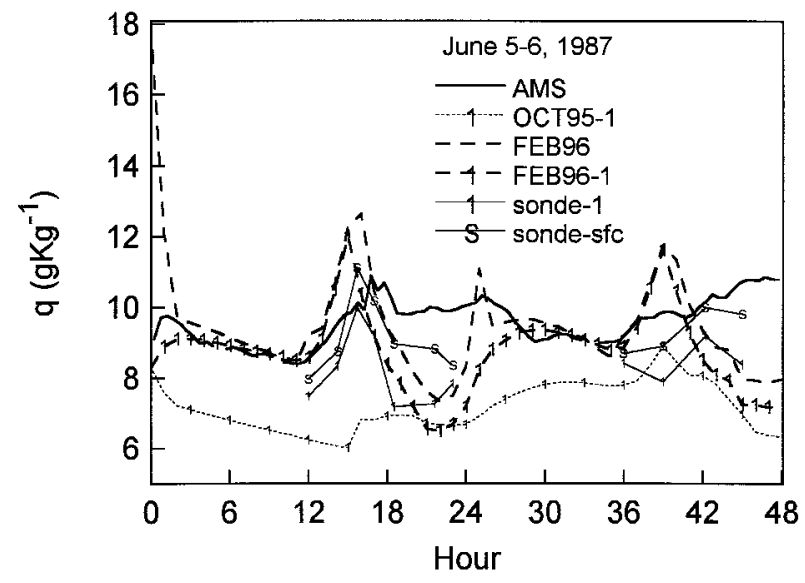

FIG. 10. (a) Comparison of near-surface potential temperature $\theta$ showing FIFE data and FEB96 model at $2 \mathrm{~m}$, sonde data at launch, and a level 60-90 $\mathrm{m}$ above surface (labeled 1), and the first model level (70 m above surface: labeled 1) for both OCT95 and FEB96. (b) As in (a) but for mixing ratio $q$.

the phasing of the sensible and latent heat fluxes. On the other hand, it controls the surface temperature in the face of model radiation errors. The FEB96 model, which has a separate skin temperature has a better phase but too large an amplitude in comparison with the data. A skin temperature, which has no thermal inertia, is very sensitive to the $R_{n}$ errors seen in Fig. 2. This larger diurnal amplitude for FEB96 mirrors Fig. 8 for the 2-m temperature, so that the difference $\left(T_{\text {sfc }}-T_{2}\right)$ has a very similar diurnal signal to the FIFE data (not shown). This lends support to the new parameterization for the roughness length for heat [based on Zilitinkevich (1995); see appendix B].

Although the 2-m diagnostic data for the OCT95 model is not useful (see appendix A), we can compare data at the lowest mode-predicted level (labeled 1 on figures), about $70 \mathrm{~m}$ above the surface. Figure 10a shows potential temperature $\theta$ for six curves. The FIFE site mean (at $2 \mathrm{~m}$ ) is the heavy solid curve, while the lighter solid lines are from the sondes (launched roughly every $90 \mathrm{~min}$ ) both at the surface (labeled S) and for a sonde level 60-90 $\mathrm{m}$ above the surface (labeled 1). The surface site mean and the surface at the sonde site are not fully consistent [the sondes were launched from a valley in the northwest corner of the $15 \times 15 \mathrm{~km}$ FIFE site, which is significantly lower than the mean station height of the AMS mean (Sugita and Brutsaert 1990a,b; Betts and Ball 1994)]. The lowest model level of the OCT95 data (shown dotted) is uncoupled from the surface in the night of 5 June and warmer than the sonde data at the corresponding height on both days. The FEB96 lowest model level data at night is more closely coupled to the surface. Clearly the revisions to the surface-BL coupling in FEB96 are an improvement in this regard. The FEB96 model has the larger diurnal amplitude seen in Figs. 8 and 9, so that near the surface, it is colder at night and warmer in the daytime than the observations. However, the daytime superadiabatic layer in the model is not inconsistent with the less frequent sonde observations (which are influenced by the inhomogeneous surface).

Figure $10 \mathrm{~b}$ shows the corresponding diurnal cycle of mixing ratio $q$ for the 2 days. The OCT95 model (dotted), for which we show only the first model level about $70 \mathrm{~m}$ above the surface, was too dry. We have seen that it has the lowest surface LH flux (Fig. 5). For FEB96 we show both the 2-m diagnosed time series and the predicted lowest model level. These are quite consistent (although the 2-m $q$ clearly has an initialization problem at time zero and a spike at $24 \mathrm{~h}$, as the model shifts from an unstable to a stable BL parameterization). For the FIFE data we show three curves. The continuous solid curve is the AMS-site average of $q$ at $2 \mathrm{~m}$. The sonde observations at the surface (labeled $\mathrm{S}$, measured near $2 \mathrm{~m}$ ) and a sonde level 60-90 $\mathrm{m}$ above the surface (labeled 1) are also shown, linked by light solid lines. We show both sets of surface data because the AMSsite average and sonde surface data are again not entirely consistent. The sonde data does show a consistent daytime gradient of $q$ off the surface of $0.5-1.5 \mathrm{~g} \mathrm{~kg}^{-1}$. In the FEB96 model, this difference may be somewhat smaller than observed in the morning. The new model FEB96 now has little bias, but it has too strong a daytime diurnal signal in $q$. The peak in $q$, evident in FEB96 a few hours after each sunrise, appears to be related to the slower morning growth of the BL in the model. On 5 June, the observations also show a peak, although not as large as in the model. On 6 June, for example, the FEB96 surface LH flux is biased low (Fig. 5), but the model has a positive $q$ bias in the morning, because the surface LH flux is distributed through too shallow a BL (see 1500 UTC in Figs. 12a,b below). The OCT95 model, in contrast, does not show these morning $q$ peaks, since it has a small or zero LH flux for several hours 
(a)

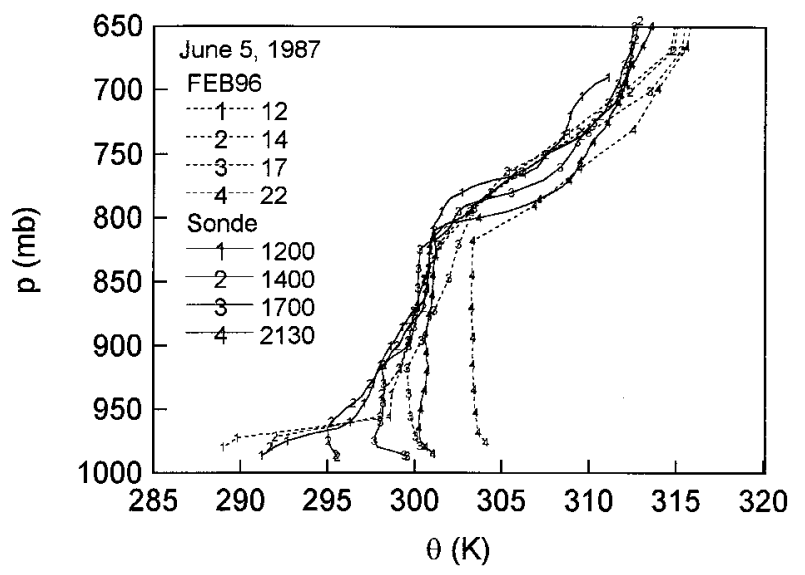

(b)

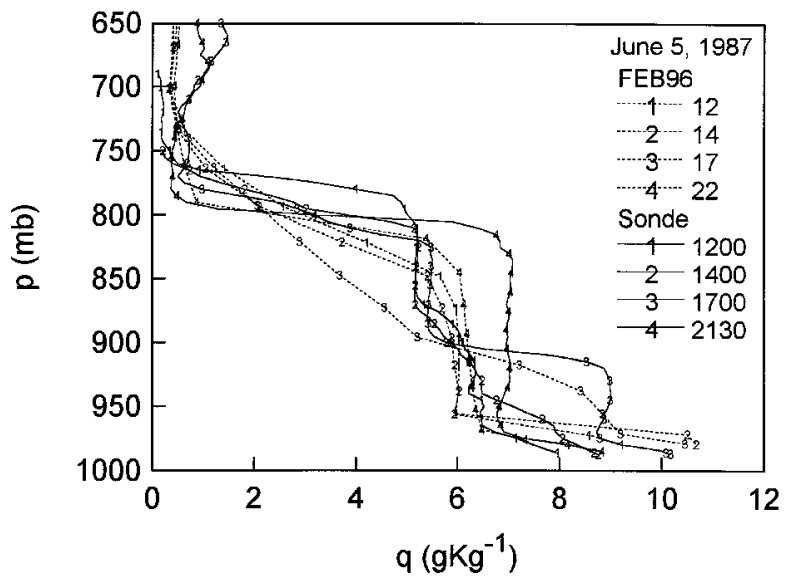

FIG. 11. (a) Comparison of FIFE sonde $\theta$ profiles near 1200, 1400, 1700, and 2130 UTC 5 June with corresponding Eta FEB96 forecast BL profiles. (b) As in (a) but for BL profiles of $q$.

after sunrise (Fig. 5), because of its early morning ground heat flux error (Fig. 4).

The larger diurnal amplitude in the FEB96 model, which we have seen in Figs. 10a and 10b, means that this model is too close to saturation near sunrise and early morning and has much too high a lifting condensation level (LCL) in the afternoon (about $1000 \mathrm{~m}$ too high on 6 June, not shown). The OCT95 model has a similar LCL to FEB96 in the afternoon (both too high). These afternoon differences from the data in LCL (not shown) follow from the flux differences seen in Figs. 5,6 , and 7. A lower surface evaporative fraction leads directly to a higher LCL (Betts 1992). This LCL forecast error has an adverse impact on the calculation of convective instability indices from the Eta Model output.

\section{c. Boundary layer evolution}

Both the Eta OCT95 and FEB96 models use the Mellor-Yamada 2.5 BL scheme, although FEB96 has some further revisions (Janjić 1996a). They differ also in their coupling of the BL scheme to the surface; in particular, the FEB96 model over land replaces the previous integrated Mellor-Yamada level-2 scheme (Lobocki 1993) with a Paulson formulation for the surface layer, a Zilitinkevich (1995) formulation for the viscous sublayer, and the Beljaars (1995) correction for free convection.

How does the FEB96 BL formulation compare with the observed evolution of the mixed layer? Figures 11a and $11 \mathrm{~b}$ compare selected model profiles of $\theta$ and $q$ from the FEB96 model with FIFE radiosondes launched at closely corresponding times on 5 June. At 1200 UTC, not long after sunrise, the model has a stronger and shallower surface inversion than the data, corresponding to the lower surface minimum temperature in Fig. 8. Despite a smaller observed surface $\mathrm{SH}$ flux, the observed mixed layer (ML) initially deepens faster than the model (compare profiles at 1400 UTC). There are two probable reasons for this: the observed nocturnal BL near sunrise (1200 UTC) has a weaker inversion than the model, and probably the effective BL-top entrainment is not as strong in the model (see below). However, after 1700 UTC, the model BL is warmer than the data, because the model surface $\mathrm{SH}$ flux is much larger (Fig. 6). Figure 11b compares the $q$ structures for the same soundings. There is some similarity in the diurnal evolution. The data, however, do not reach as high surface mixing ratios in the morning (see Fig. 10b), as moisture is mixed a little deeper; the observed mixed layer $q$ reaches a maximum at 1700 UTC, and then falls as the ML deepens rapidly into a preexisting deep ML (Fig. 11a). In the model, the BL is a little shallower and $q$ falls to lower values in the afternoon, presumably because the surface LH flux is less.

Figures $12 \mathrm{a}$ and $12 \mathrm{~b}$ show a similar comparison for the next day, 6 June, the second day of the Eta forecast. In Fig. 12a, the difference in BL depth at 1500 UTC is greater than the previous day. Once again, part of this is due to a more stable structure in the model at sunrise (in the data we see fragments of an ML from the previous day). As we commented above, this shallow morning BL in the FEB96 model leads to the spurious 1500 UTC $q$ peak seen in Fig. 10b, despite a lower LH flux in the model than in the data. By afternoon, the model is again much warmer than the sonde data, consistent with the rise of surface $T$ seen in Fig. 8 and the much larger model SH flux in Fig. 6 (which comes from the solar radiation error and the low EF). Note, however, that the observed BL not only deepens more rapidly, but reaches a (slightly) greater depth in the afternoon, despite much smaller surface heating all day. This again must be linked to the model not representing sufficient BL-top entrainment. The 
(a)

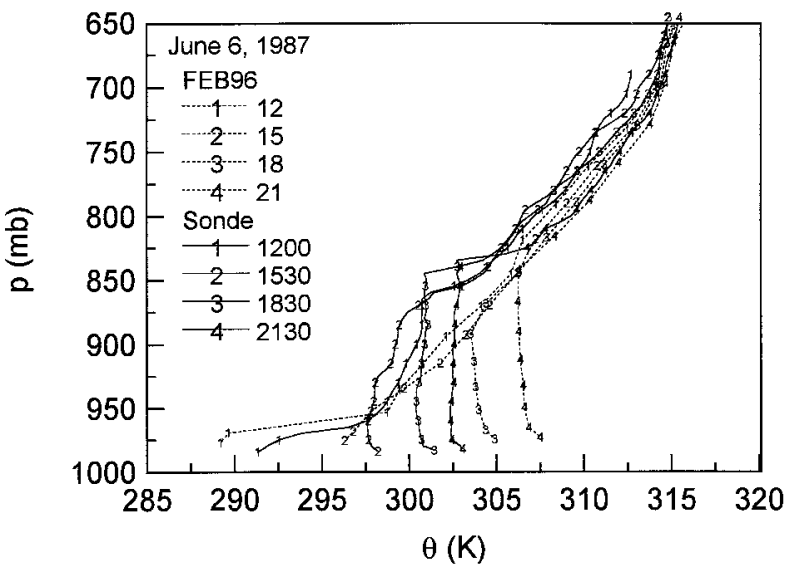

(b)

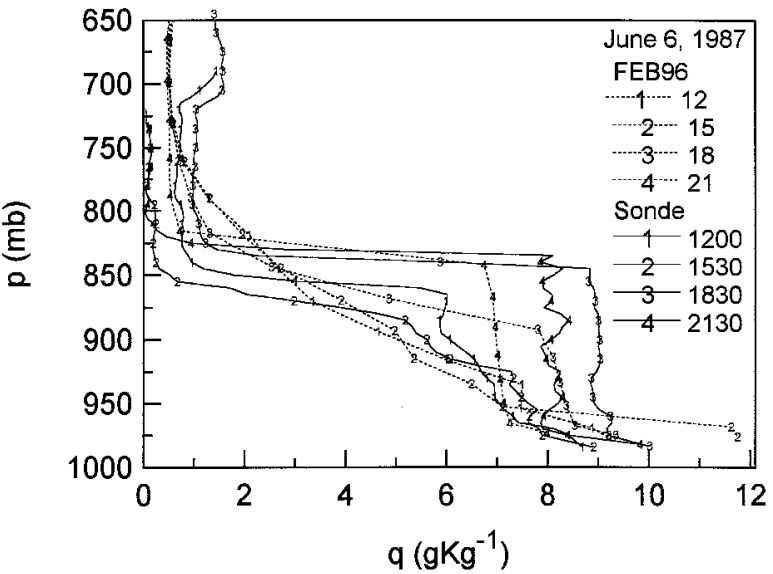

FIG. 12. (a) As in Fig. 11a but for 6 June. Comparison times are here 1200, 1530, 1830, and 2130 UTC. (b) As in (a) but for BL profiles of $q$.

model BL evolution in Fig. 12a shows no sign of the overshoot cooling at BL top produced by entrainment, which produces the distinct stable layer at the top of the mixed layer seen in the observed sonde sequence (Betts 1974). Studies of the FIFE data (Betts 1992; Betts and Ball 1994; Betts and Barr 1996), using both aircraft and sonde data, have shown that the BL evolution in FIFE implies rather high entrainment rates. Figure 12b is consistent with Fig. 12a. The spurious model morning $q$ peak, which we saw earlier in Fig. $10 \mathrm{~b}$ at 1500 UTC comes from pumping the (too small) surface LH flux into a shallow BL. The afternoon model $q$ in the $\mathrm{BL}$ is drier than observed. This is consistent with the lower LH fluxes in the FEB96 model than the data on June 6 (Fig. 5).

The FEB96 BL model with the Paulson surface layer (Chen et al. 1997) appears to be an improvement over the OCT95 model in the morning hours. Figure 13 shows the comparison of the OCT95 model with the

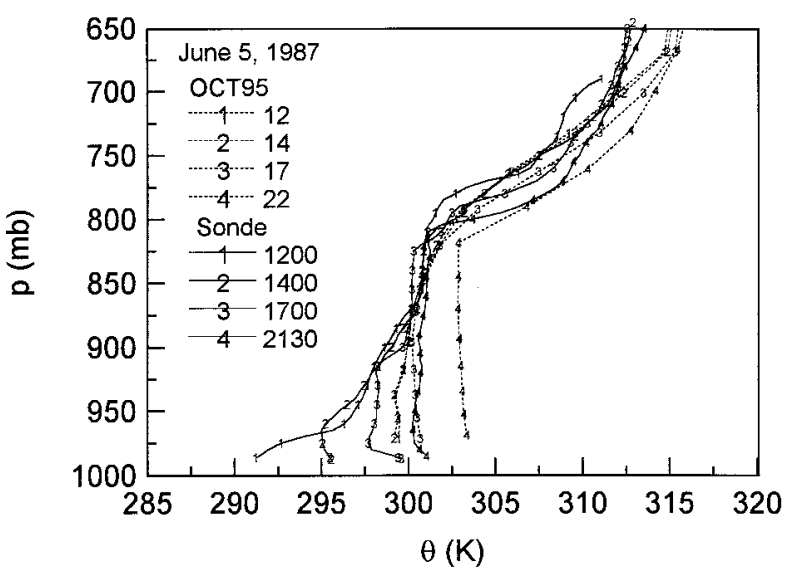

FIG. 13. As in Fig. 11a but for Eta OCT95 profiles (excluding diagnosed 2-m data).
FIFE soundings, corresponding to Fig. 11a. In this we have not plotted the 2-m data, since this was diagnosed incorrectly. The ML has not reached the first model level at 1200 and 1400 UTC, and so it is not visible (at sunrise, the surface inversion is all below the first model layer, and the SH fluxes are zero until the ground warms; see Fig. 6). Since the OCT95 model has a lower SH flux (Fig. 6), the afternoon BL is a little cooler than in Fig. 11a for the FEB96 model and therefore closer to the observed afternoon $\theta$ structure.

The differences from the data in the late afternoon state of the FEB96 model are largely due to the differences in the surface fluxes seen in Figs. 5 and 6 (although the different evolution of BL depth plays some role). The problems with the surface fluxes are several. The fall of EF from day 1 to 2 of the FEB96 Eta forecast is an internal model problem (see section 6). Why EF is low in the FEB96 model initialized from the global reanalysis is a separate issue. One reason is the large SH flux, itself linked to the large positive error in the incoming solar radiation, as mentioned above. The downward adjustment made to the global soil moisture for high values (appendix B) may also be partly responsible. However, since it had not rained at the FIFE site for 2 days in the global reanalysis model, and this global model (with the same two-layer soil physics) also has a similar problem to the dry down of the upper 10-cm layer (Betts et al. 1996a), it is likely that the initialization of the Eta soil moisture was simply unrealistic. We will discuss soil moisture initialization a little more later. The FEB96 BL model is also deficient in BL-top entrainment. This has been a common problem in large-scale models (Betts et al. 1993; Betts et al. 1996a). Even if the surface fluxes are correct, the model will not correctly represent the diurnal evolution of the BL, until BL-top entrainment is increased in the model. The anomalous surface $q$ be- 
(a)

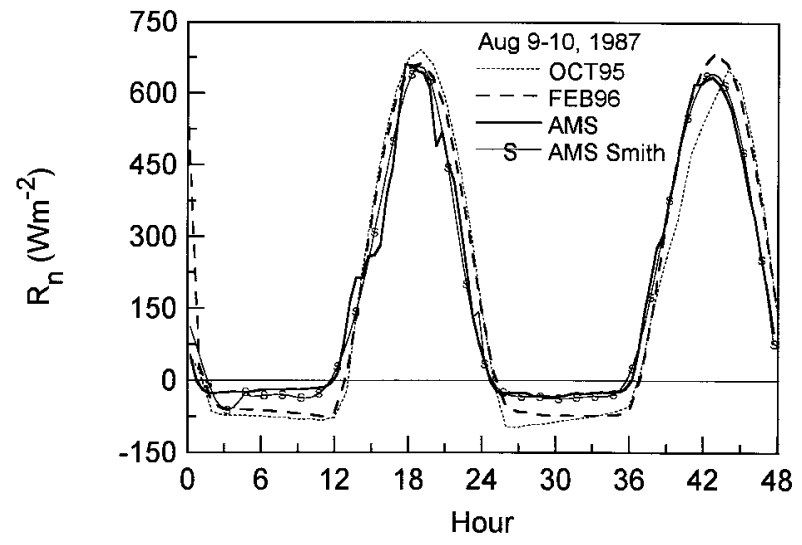

(b)

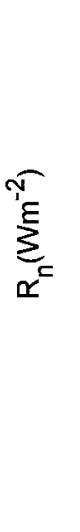

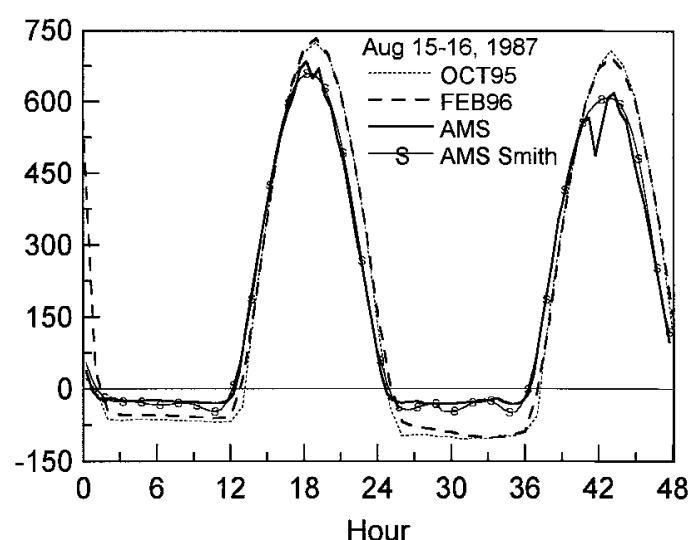

FIG. 14. (a) The $R_{n}$ comparison for 9 and 10 August. (b) As in (a) but for 15 and 16 August.

havior in Fig. 10b is related to the fact that the BL does not grow deeply enough in the morning after sunrise. In the FEB96 model, morning BL growth is suppressed not only by low entrainment, but also by the very stable structure at sunrise, because of the low surface temperature minimum. The OCT95 model has a different problem representing morning BL growth, because the warming of the slab soil model delays the sensible and latent heat fluxes to the atmosphere.

\section{Pairs of forecasts in August}

We then ran pairs of 2-day forecasts for the OCT95 and FEB96 models starting from 0000 UTC 9 and 15 August. These bracket the major rainfall event of 12 13 August. Betts et al. (1996a) have described how the global Medium Range Forecast Model used in the reanalysis handles this dry to wet transition in the soil moisture. The upper $10-\mathrm{cm}$ soil layer is resaturated, but even this heavy rainfall only increases the soil moisture of the lower 190-cm layer by less than $2 \%$, simply because the layer is so thick. We have used soil moisture derived from this global reanalysis to initialize the FEB96 Eta Model (which uses a similar twolayer OSU soil model with the same $10-\mathrm{cm}$ and $190-\mathrm{cm}$ soil layers, because it is initialized from the global model), so it is of interest to see how the FEB96 version of the Eta Model describes the diurnal cycle before and after the rainfall. It is likely that more vertical resolution in the soil would improve the response to soil moisture changes on different timescales, but until this is implemented in either the global or Eta models, we can draw no firm conclusions. In contrast, the OCT95 model, which uses prescribed bucket soil moisture, does not know about the intervening rainfall event. These pairs of days are without rain and have only scattered cloud, but from a synoptic viewpoint there appears to be significant cool dry advection on 9 and 16 August. In our single station analysis, we cannot separate errors in the synoptic advection from errors in the diurnal cycle on these 2 days.

\section{a. Surface fluxes}

Figures $14 \mathrm{a}$ and $14 \mathrm{~b}$ show the net radiation for the two models and the data for the 4 days. All 4 days were relatively sunny in both data and model. As in Fig. 2, the model curves are generally the highest in the daytime and the lowest at night. This is again largely due to much larger incoming shortwave (SW) radiation (not shown) in the model in the daytime, partly offset by a higher model albedo and a higher FEB96 surface temperature on 9-10 August (see Fig. 16). At night, low incoming LW radiation (not shown) is again responsible for the larger model net outgoing radiation. The ground heat flux pattern (not shown) is similar to Fig. 4.

Figures $15 \mathrm{a}$ and $15 \mathrm{~b}$ compare the surface $\mathrm{LH}$ and SH fluxes for 9-10 and 15-16 August. In the data, evaporation is naturally higher after the heavy rainfall but changes little on the second day of each pair. In the OCT95 model, which uses a bucket scheme initialized with a prescribed water depth, the LH flux is less than observed both before and after the rain, and falls on the second day of each pair for the same reason discussed after Fig. 5. For the OCT95 model, the LH flux does increase from 9 to 15 August, not because initial bucket soil water increases, but because wind speeds are higher on 15 August. In the FEB96 model, evaporation is low and constant before the rain but falls sharply from 15 to 16 August from being high to being low relative to the data. The model low evaporation bias before the rain event illustrates again the difficult problem of soil moisture initialization. We have used the soil moisture fields from the reanalysis (adjusted as described in appendix B). However, as shown in Fig. 7 of Betts et al. (1996a), the MRF reanalysis had very little rainfall on 3-4 August, but there 
(a.1)

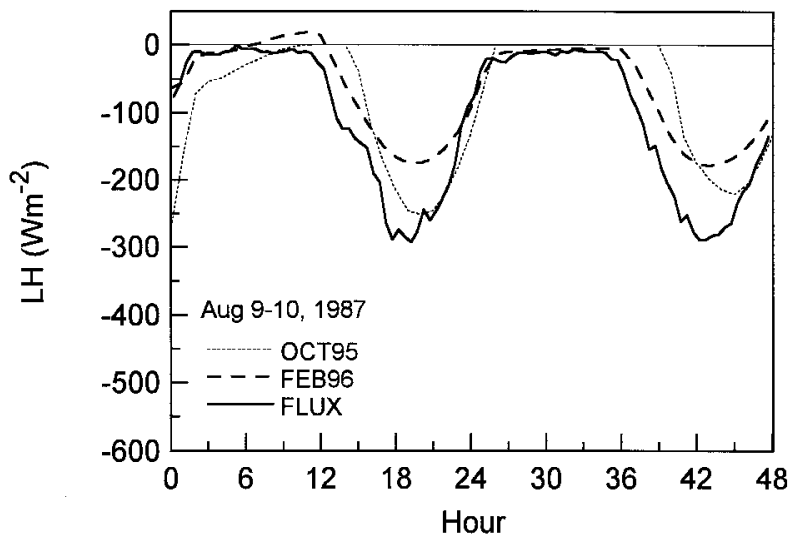

(a.2)

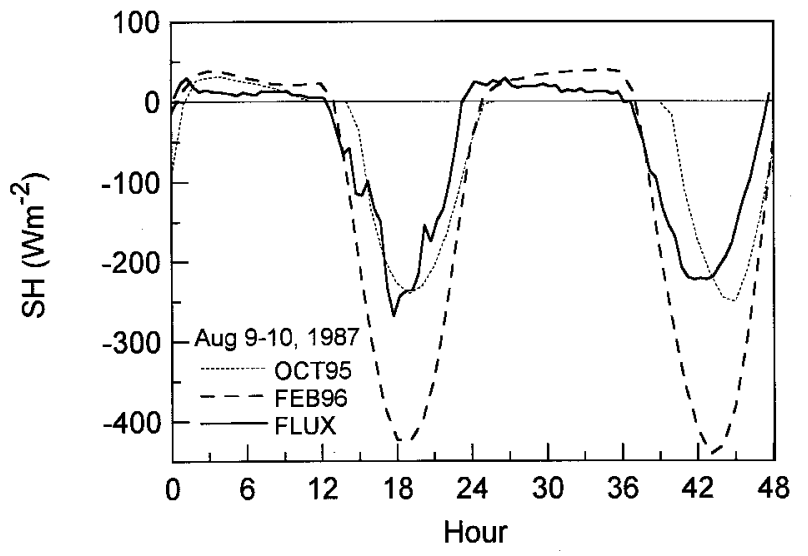

(b.1)

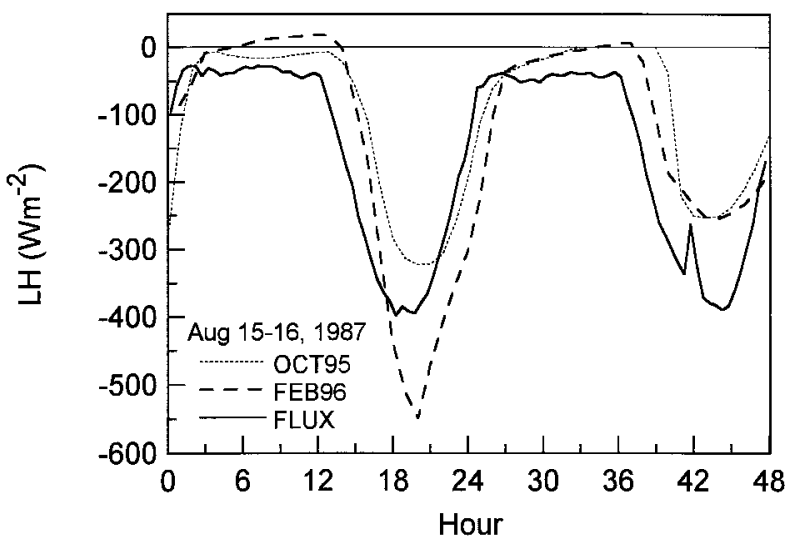

(b.2)

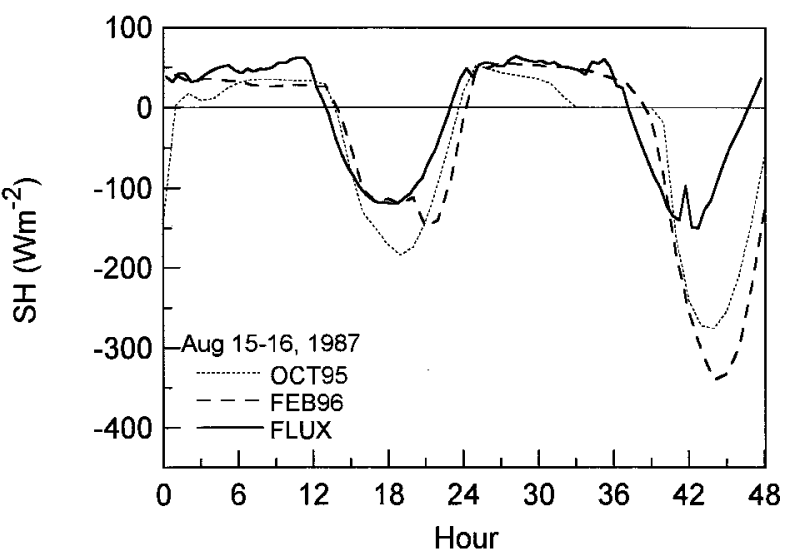

FIG. 15. (a) The LH and SH comparisons for 9 and 10 August. (b) As in (a) but for 15 and 16 August.

was significant rainfall at the FIFE site, which partially restored the observed soil moisture after a long drought. (However, with the relatively low vegetation fraction in the reanalysis model, soil moisture in the first $10 \mathrm{~cm}$ would probably have been depleted by 9 August, even if there had been rain in the model on 3-4 August.) Not having the correct soil moisture (or the right vegetation fraction), we cannot expect the Eta Model to give the right fluxes. In this case, before the heavy rainfall (which was seen in the reanalysis), the OCT95 bucket model with seasonally prescribed soil moisture fortuitously predicts the evaporation better than the two-layer FEB96 model. After the rainfall, the bucket model responds only to the higher wind speeds, while the FEB96 model overresponds as it sees both the higher winds and a larger soil moisture, and has a strong direct soil evaporation, because the vegetation fraction is too low. Because of the low LH fluxes and the positive $R_{n}$ bias, the FEB96 model has roughly double the observed SH flux for 9-10 and 16 August (Figs. 15a,b). This naturally leads to a large positive error in the daytime surface temperature (Figs. 16a,b).
The surface flux trends for the 15-16 August pairs are similar to those shown for 5-6 June (Figs. 5, 6). Tests of some improved model components will be discussed in section 6 .

\section{b. Surface diurnal cycle}

Figures 16a and 16b compare the surface temperature for the pairs of days before and after the rainfall. As in Fig. 9, the OCT95 model (which has the inertia of the $10-\mathrm{cm}$ soil slab temperature) is closer to the observations in the daytime but falls more slowly at night. The FEB96 model skin temperature is biased high at local noon on all days (except 15 August), in agreement with the low LH and high SH flux bias. The FEB96 skin temperature falls almost $7 \mathrm{~K}$ below that observed at dawn on 16 August. The downwelling LW in the model is about $70 \mathrm{~W} \mathrm{~m}^{-2}$ less than observed during this night. In fact, the nighttime pattern of the downwelling LW radiation for both models and data qualitatively resembles Fig. 3 on all nights (not shown). On average, the downwelling LW radiation in FEB96 at dawn is $35 \mathrm{~W}$ 
(a)

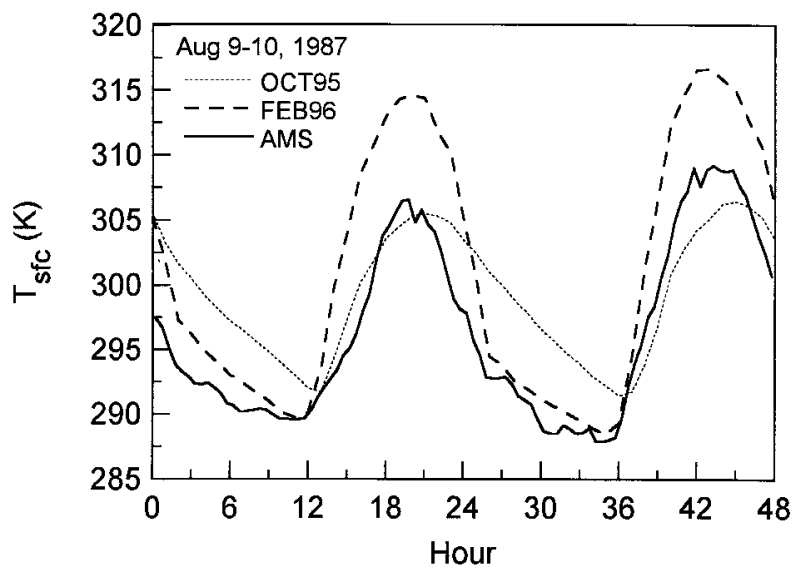

(b)

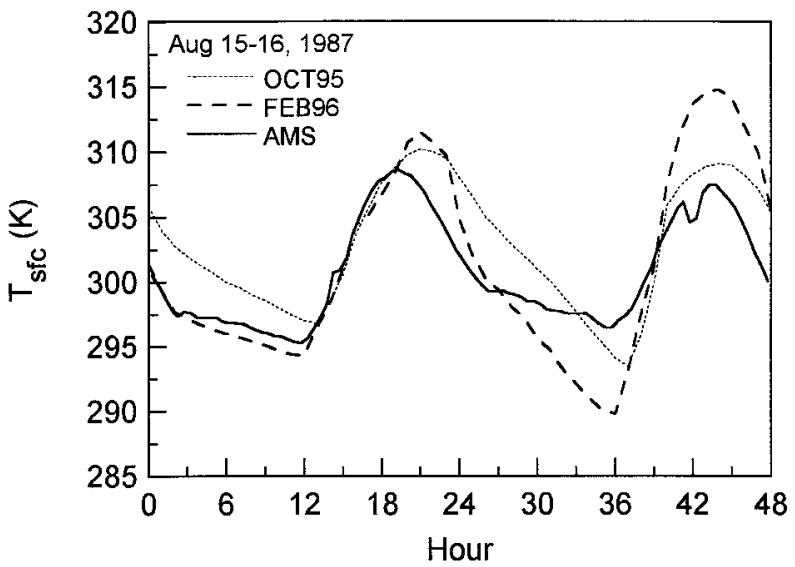

FIG. 16. (a) Surface temperature comparison for 9 and 10 August. (b) As in (a) but for 15 and 16 August.

$\mathrm{m}^{-2}$ less than observed. This needs further study, as it could be caused by errors in the model clear-sky LW code, or by underestimation of cloud cover, or perhaps even by a positive internal model numerical feedback between the falling skin temperature and the incoming LW radiation.

Figures $17 \mathrm{a}$ and $17 \mathrm{~b}$ compare the potential temperature at the surface for the two pairs of days. As in Fig. 10a, the site-averaged PAM (Portable Automated Mesonet) data tend to be slightly warmer than the sonde surface data. For 9-10 August before the rain event, FEB96 (as seen in Fig. 16a for the skin temperature) has a warm daytime bias (because of higher SH flux) but no predawn bias. For 15-16 August the daytime positive bias is smaller, but FEB96 is here much cooler at sunrise, and this cold bias increases on the second day. As mentioned above, this appears to be associated with much lower incoming LW radiation from the atmosphere than observed. The $\theta$ gradient between sur- face and $70 \mathrm{~m}$ for FEB96 is similar to that observed, although the only sonde data for the stable situation is near sunrise at 1200 UTC. For the OCT95 model, since there is no good 2-m data, we show only the first model level near $70 \mathrm{~m}$. The striking feature here (as in Fig. $10 \mathrm{a})$ is that this first model level cools much less in the OCT95 model. On some nights (10 and 16 August, as well as 5 June), $\theta$ cools little at $70 \mathrm{~m}$ in the OCT95 model, so that the atmosphere and surface completely uncouple.

Figures $18 \mathrm{a}$ and $18 \mathrm{~b}$ show the corresponding mixing ratio q comparisons for 9-10 and 15-16 August. Model and data track quite well during 9 August, although FEB96 falls farther, but on the second day, 10 August, both models are drier than observed. This is consistent with them both having a smaller surface LH flux than observed. The gradient of $q$ off the surface in FEB96 is similar to that observed in the sonde data. For 15 August, the FEB96 model shows a sharp morning $q$ peak

(b)

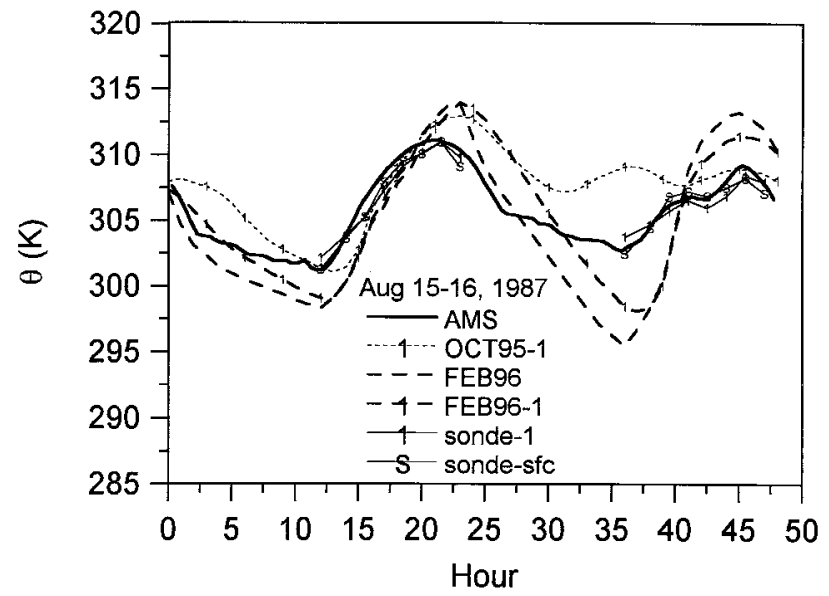

FIG. 17. (a) As in Fig. 10a but for 9 and 10 August. (b) As in (a) but for 15 and 16 August. 
(a)

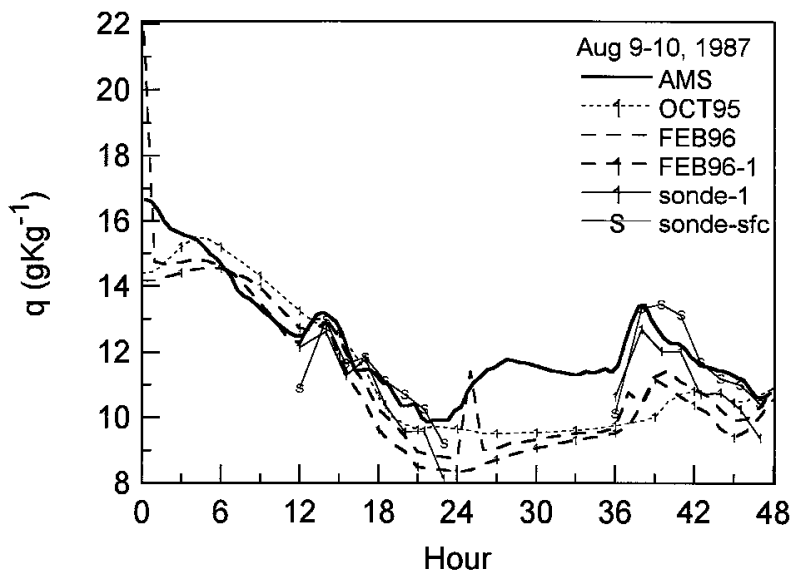

(b)

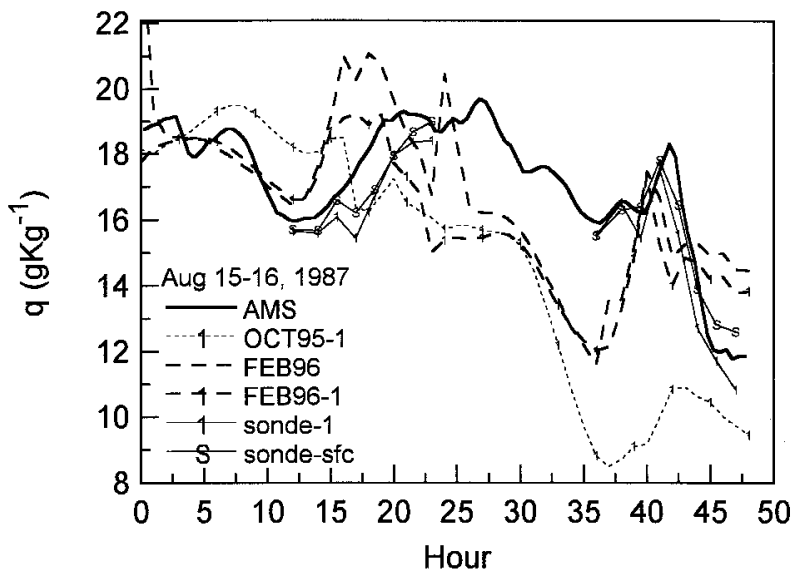

FIg. 18. (a) As in Fig. 10b but for 9 and 10 August. (b) As in (a) but for 15 and 16 August.

(presumably because it has both a shallower BL and a larger LH flux). Both models experience very dry advection for the 15-16 August night (not shown). Both models have too small an LH flux on the second day of 16 August; FEB96 briefly gets as moist as the data at the surface (since it has again a very shallow morning $\mathrm{BL})$. The OCT95 model is dry compared to the data all day, because its LH flux is low, but its BL depth is deeper than the FEB96 model (the nighttime thermal advection appears to be different).

\section{c. BL structure}

Figures 19a and 19b compare the BL $\theta$ profiles for FEB96 and OCT95 models for 9 August with FIFE sondes selected to be within $30 \mathrm{~min}$. Both models are initially warm at sunrise below $800 \mathrm{mb}$. As in the 5-6 June case, the BL in the OCT95 model is less coupled to the surface than in the FEB96 model, and the first model $\theta$ level cools less at night. Not surprisingly, the FEB96 model with the larger SH flux attains a deeper warmer BL in the afternoon than the OCT95 model. Both are warmer than the observed BL. The FEB96 BL reaches almost the BL depth observed, although its $\mathrm{SH}$ flux is far larger than observed $\left(430 \mathrm{~W} \mathrm{~m}^{-2}\right.$ at local noon, as opposed to $250 \mathrm{~W} \mathrm{~m}^{-2}$ observed), while the OCT95 model with a more realistic SH flux has too shallow a BL. The reason again must be that both $\mathrm{BL}$ models do not adequately represent the BL top entrainment process, which significantly warms and deepens the BL.

Figure 20 shows the interesting evolution of the BL $\theta$ profile on 10 August as the FEB96 model BL deepens rapidly through the morning hours. There is an unrealistic superadiabatic layer high in the BL, suggesting that the FEB96 model transfer coefficients in this region are too low. The long time step of $800 \mathrm{~s}$ used in the $80-\mathrm{km}$ version of the Eta Model is partly responsible for this (a)

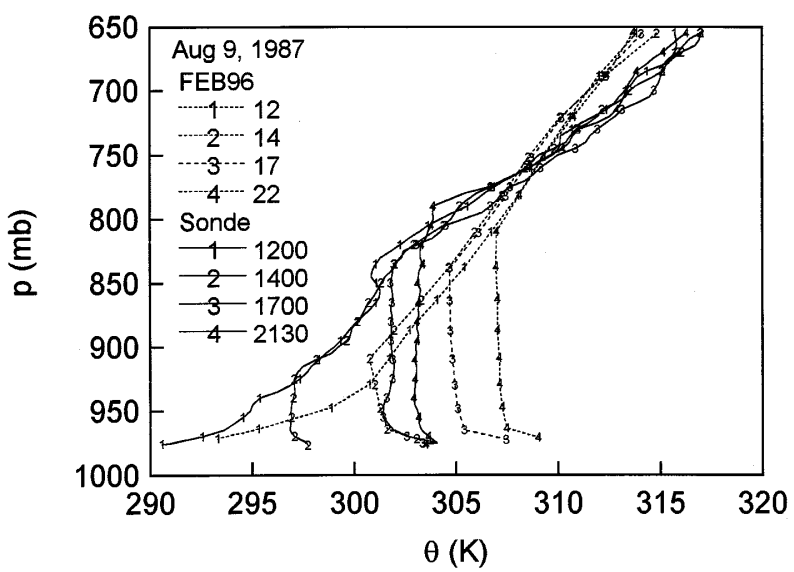

(b)

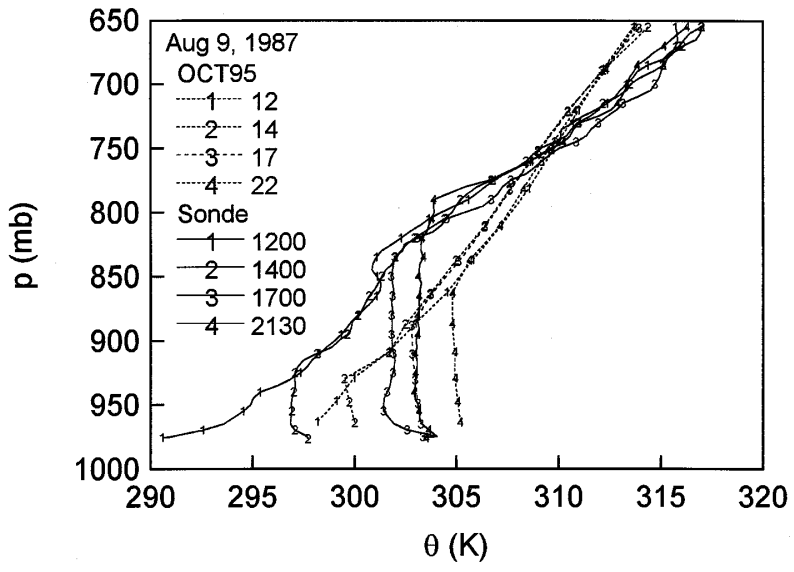

FIg. 19. (a) Sonde comparison for FEB96 and data for 9 August. (b) Sonde comparison for OCT95 and data for 9 August. 


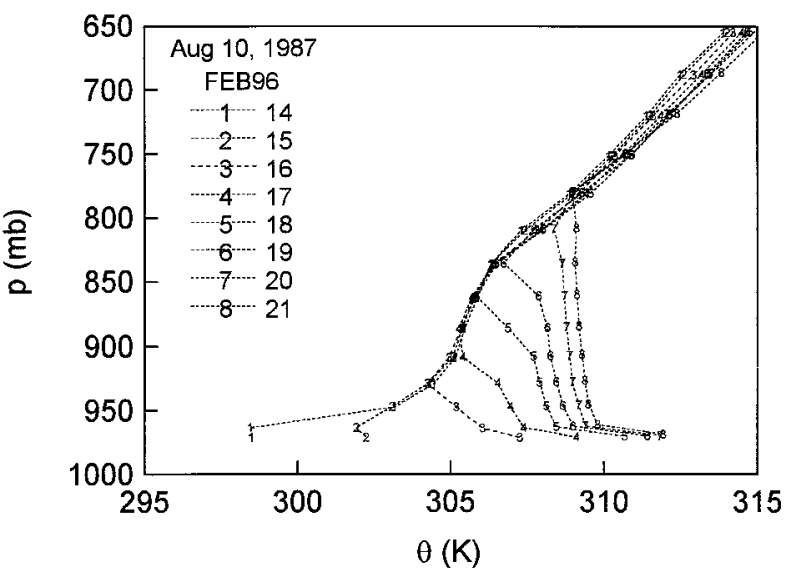

FIG. 20. Time sequence of FEB96 model soundings on 10 August.

slow response of the BL scheme to the large $\mathrm{SH}$ flux of $400 \mathrm{~W} \mathrm{~m}^{-2}$. This problem is reduced with the shorter time step used in the current $48-\mathrm{km}$ grid operational model. However, again there is no entrainment overshoot cooling process visible (Betts 1974) where the growing BL meets the preexisting sounding above.

Both models represent the evolution of the much shallower BL on 15 August quite well (not shown).

\section{8 July rain event}

We also ran 2-day forecasts for 8-9 July. However, it rained for most of 8 July in both model versions, while there was only a brief shower in the night before sunrise in FIFE, so the daytime comparison of model and data is of limited use. The FEB96 run does illustrate the new model formulation of the surface evaporation and reminds us of the difficulties that models have with cloud fields and the radiation balance. Figure 21 shows the incoming solar radiation for 8-9 July, observed and modeled, and the model precipitation. The usual high bias of the model incoming solar flux is gone, but it is raining in the model, and not for the daytime obser-

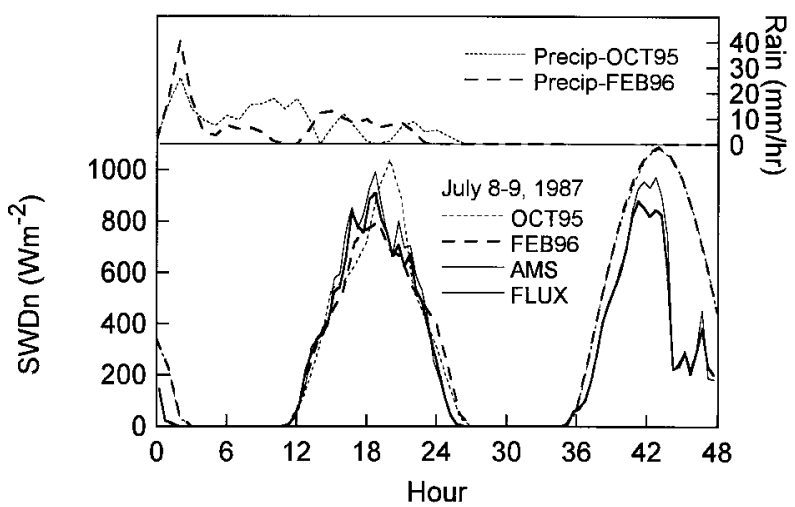

FIG. 21. Comparison of incoming solar radiation for 8 and 9 July. Upper curves are model precipitation.

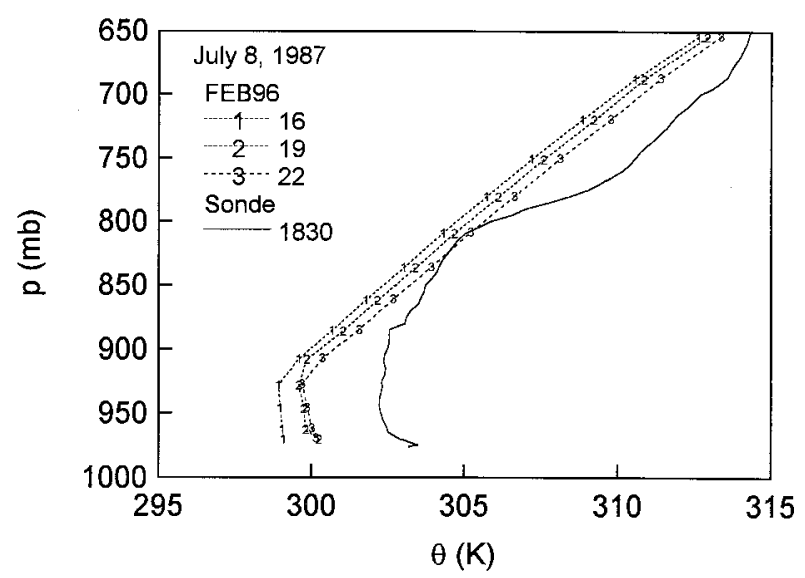

FIG. 22. FEB96 model $\theta$ soundings during rain and a comparison FIFE sounding for 8 July.

vations! The reduction of the incoming solar flux during rain in the model of order $300 \mathrm{~W} \mathrm{~m}^{-2}$ is much less than typically observed on rainy days in FIFE (Betts et al. 1996a). Models need to represent the negative feedback of clouds on the incoming SW more realistically, particularly during precipitation episodes. During this 8 July rainfall event, the FEB96 model has high potential evaporation at the surface, because of high net radiation on a wet canopy. However, unlike similar days at this location in the MRF model (Betts et al. 1996a), the interaction between the convective BL and surface schemes is able to maintain a shallow but unsaturated BL during the rain. Figure 22 shows the FEB96 model profiles of $\theta$. There is shallow nearly constant ML from surface to $920 \mathrm{mb}$ in the model, cooler than the data (because the surface SH flux in the model is low, not shown), and a uniform (and unsaturated, not shown) structure above, being tightly maintained by the convective adjustment scheme (Betts and Miller 1986; Janjić 1990, 1994). The observed profile at 1830 UTC shown (where it is not raining) has a mixed layer to 880 $\mathrm{mb}$ and a cumulus layer above to about $780 \mathrm{mb}$. The OCT95 model (not shown) has by afternoon on 8 July a much deeper and warmer BL, because it has a higher sensible heat flux, but a similar control on the thermodynamic structure above cloud base by the convective adjustment scheme.

\section{Sensitivity of evaporation of FEB96 model to vegetation fraction and soil evaporation model}

The sharp fall of evaporation in the FEB96 model from the first to second day of integration seen in Figs. 5 and $15 \mathrm{~b}$ was unexpected, so we investigated further. This model calculates evaporation $E$ as the sum

$$
E=E_{t}+E_{\mathrm{dir}}+E_{c},
$$

where $E_{t}$ is evapotranspiration, $E_{\mathrm{dir}}$ is direct evaporation from the soil, and $E_{c}$ is reevaporation of precipitation 


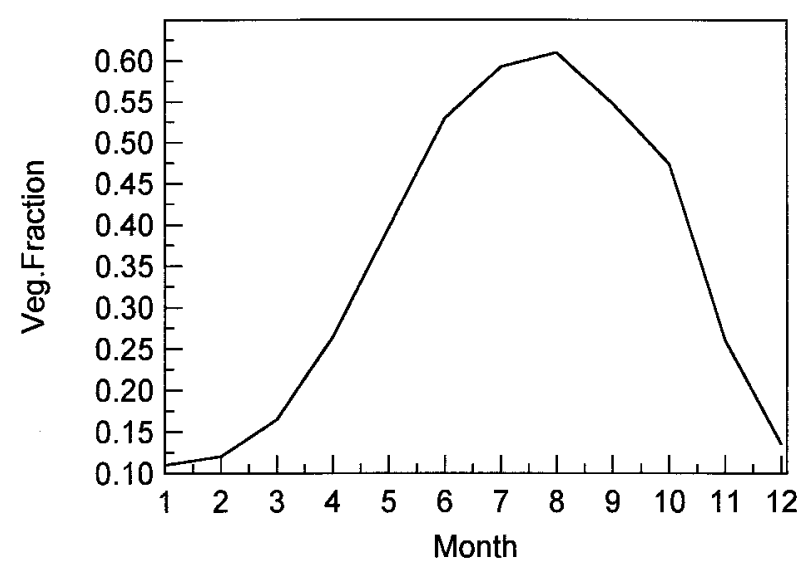

FIG. 23. Seasonally prescribed vegetation fraction in FEB96.

intercepted by the canopy. The canopy evaporation $E_{c}$ is zero for the two integrations in Figs. 5 and 15b. The partition of $E$ between the remaining two terms depends on the vegetation fraction, which has a specified seasonal cycle at each grid point. Figure 23 shows the specified seasonal cycle at our FIFE grid point. It is only 0.54 in June and is about 0.6 in July and August. Consequently, in June $46 \%$ of the surface is modeled with bare soil evaporation, with $E_{\text {dir }}$ calculated using Mahrt and Pan (1984), based on the so-called threshold method. The direct evaporation $E_{\text {dir }}$ proceeds at a potential evaporation $E_{\text {pot }}$ rate down to a soil moisture threshold and then falls sharply with further decreases of soil moisture. In addition, unlike evapotranspiration, which extracts soil moisture from both the shallow $10-\mathrm{cm}$ layer and the deep 190-cm layer, $E_{\text {dir }}$ only extracts moisture from the first shallow layer. With $46 \%$ bare soil, $E_{\text {dir }}$ is a major term, and its contribution is initially large and falls markedly on day 2 following the depletion of the $10-\mathrm{cm}$ layer soil moisture on day 1 . This is the explanation for the model behavior on 5-6 June and 15-16 August. For 9-10 August, soil moisture in the first layer is so low that $E_{\mathrm{dir}}$ is very small, and consequently $E$ is low.

This raises both the issues of both the specification of vegetation fraction and the direct soil evaporation function. Figure 24 shows a sensitivity test for 5-6 June of using in the Eta Model a preliminary version of a more recent satellite-derived 5-yr climatology of vegetation fraction (Gutman and Ignatov 1996). At the FIFE site, this climatology has a much higher (and more realistic) June vegetation fraction of 0.83 . The model LH flux (fine solid line) increases significantly as $E_{t}$ is more important, and the fall of evaporation from the first to second day is greatly reduced. The noon peak of the model SH flux (not shown) is correspondingly reduced to about $275 \mathrm{~W} \mathrm{~m}^{-2}$, still much larger than the observations (Fig. 6), as $R_{n}$ is too large in the model. However, since we have no absolutely reliable soil moisture values, and the dependence of vegetation resistance on soil moisture has itself been tuned (Chen et al. 1996a), it is

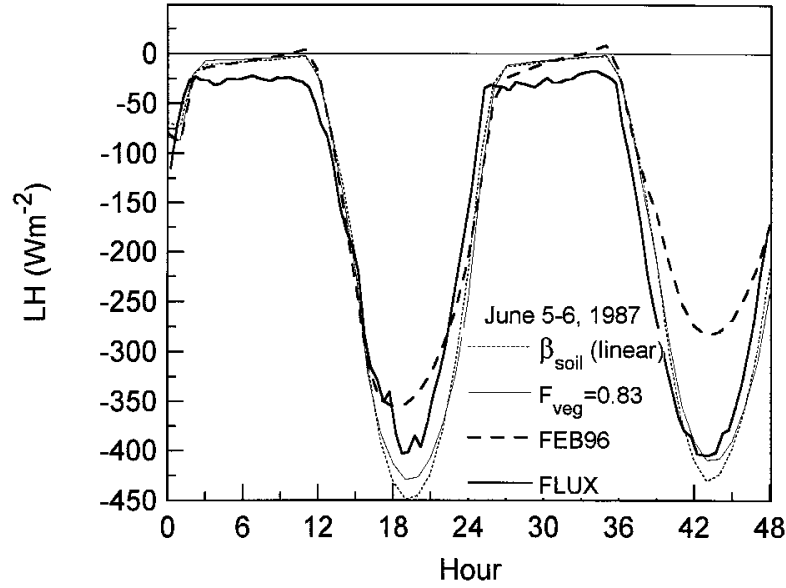

FIG. 24. Sensitivity tests of dependence of LH flux on vegetation fraction and direct soil evaporation model for FEB96 model.

clear that a more realistic vegetation fraction will significantly improve the fit to the data.

The other sensitivity test we tried was to change the function for $E_{\mathrm{dir}}$. We investigated a simple linear $\beta$ method (Mahfouf and Noilhan 1991),

$$
E_{\mathrm{dir}}=\beta E_{\mathrm{pot}},
$$

where

$$
\begin{aligned}
\beta= & \left(\mathrm{SM}-\mathrm{SM}_{\text {wilt }}\right) /\left(\mathrm{SM}_{\text {ref }}-\mathrm{SM}_{\text {wilt }}\right), \\
\text { with } & \mathrm{SM}_{\text {ref }}=0.39, \text { and } \mathrm{SM}_{\text {wilt }}=0.12 .
\end{aligned}
$$

This greatly smooths the fall of $E_{\text {dir }}$ with first-layer soil moisture in comparison with the threshold method of Mahrt and Pan (1984). The dotted curve in Fig. 24 uses Eq. (2) and the small vegetation fraction of 0.54 . The result is rather similar to changing vegetation fraction to 0.83 (fine solid line). An important physical difference is that increasing vegetation fraction extracts more water from the deep soil layer and less from the first 10-cm layer, while using (2) for $E_{\text {dir }}$ extracts more water from the first layer, so that its soil moisture falls faster. In forecasts longer than 2 days, this would be significant, but in the 48-h Eta forecasts both sensitivity tests in Fig. 24 give similar results, at least for this one grid point. Clearly, getting evaporation correct over arid areas, where vegetation fraction is small, will require more attention to these model parameterizations. These two model revisions, namely Eq. (2) for the bare soil evaporation and a new satellite-derived vegetation climatology, will be incorporated in the next operational version of the Eta Model.

\section{Conclusions}

The NCEP Eta Model was designed as a short-term mesoscale forecast model for North America. Its skill in forecasting precipitation and storm systems has been documented elsewhere (Black et al. 1989; Black 1994; Lanzic 1990, 1993a,b; Mesinger 1996; Mesinger and 
Black 1992; Mesinger et al. 1997), using case studies and precipitation statistics. The Eta Model is also being used to produce an archive of near-surface meteorological variables, surface fluxes, and subsurface variables, as well as synthetic soundings across the Mississippi basin for GCIP. One use of these model products is to derive the atmospheric hydrologic budget for the Mississippi River subbasins (Berbery et al. 1996). In turn, it is expected that comparison of these hydrologic budgets and model surface fluxes with estimates based on hydrological models as well as surface flux measurements, where available, will lead to improvements in the Eta Model physical parameterizations. As one step in this process, we have used the 1987 FIFE data to understand some characteristics of the surface components in the operational Eta Model used for the GCIP archive for 1994 (GIST) and 1995 (ESOP-95); and the FEB96 version of the model, which was the operational Eta model from 31 January 1996 to 18 February 1997.

The biggest change from the OCT95 to the FEB96 model is in the handling of the soil hydrology and soil thermal transfer. The OCT95 bucket model hydrology and soil-slab thermal model has been replaced in the FEB96 model with a derivative of the Pan and Mahrt (1987) OSU model. This includes a two-layer soil hydrology and vegetation model, a skin temperature, and different soil conduction equation. Some improvements are readily visible. The $10-\mathrm{cm}$ slab-soil model had an unrealistic ground heat flux and subsequent early morning phase errors in the sensible and latent heat. (These could, however, have been reduced by introducing a thinner first soil layer.) The introduction of the skin temperature in the FEB96 gives a more realistic ground heat flux and better phasing of the surface SH and LH fluxes. However, since this "skin" has no thermal inertia, it is sensitive to errors in the surface radiation budget. Because incoming net radiation is too large in the daytime and outgoing net radiation is too large at night, the skin and surface temperatures have too large a diurnal amplitude. In this respect, the finite thermal inertia of a slab (preferably thinner than $10 \mathrm{~cm}$ ) is less sensitive to such forcing errors.

The changes in the soil-vegetation-evaporation model can only be partially assessed in this study. Chen et al. (1996) concluded from offline integrations and comparisons with the FIFE data for the summer of 1987 that the OSU model was superior to the bucket model in its ability to represent the diurnal and seasonal evaporation. Indeed, they used the FIFE time series to partially tune the coupling of soil moisture to evaporation in this model. Our comparisons of 2-day forecasts with some of the same FIFE data are very different from these offline seasonal integrations, initialized with soil moisture in late May and run for 5 months driven by near-surface observations. Here we are only looking at the diurnal cycle of the surface fluxes, not the seasonal cycle. The atmospheric variables are not specified at the surface in the course of the integration, as we are using the full interactive model. Now, however, accuracy in the modeled surface fluxes depends (among many others) on three critical factors: the modeled incoming SW and LW radiation, the model specified green vegetation fraction, and initial conditions of soil moisture (largely model-driven during data assimilation). Together with the initial atmospheric conditions, the initial model soil moisture was taken (with some correction at high soil moisture) from the NCEP-NCAR global reanalysis for 1987, which used the global MRF model. (The same version at a higher T-126 resolution was the operational MRF model in 1995.) Although the MRF model also uses a version of the OSU soil-hydrology-vegetation model, there are many differences in its physical parameterizations, which lead to differences in the forecast precipitation at the FIFE site in 1987 (Betts et al. 1996a). Some of the biases in evaporative fraction, seen in individual forecasts here, may come directly from the initial soil moisture conditions, derived from the MRF reanalysis fields. This difficult issue of soil moisture initialization has not been fully resolved at any global forecast centers. A fully continuous data assimilation over North America using the Eta Model, which is under development (Rogers et al. 1995), will remove the current differences in physical parameterizations between (global) analyses and the regional Eta forecasts. An offline land data assimilation system, driven by observed hourly precipitation fields and hourly net radiation, derived from geostationary satellite data, is also planned as an alternate strategy for deriving soil moisture for initialization, as there is no assurance that model errors, particularly in the surface radiation budget, will not lead otherwise to long-term drifts in soil moisture. Other forecast centers have found this to be so (Viterbo and Beljaars 1995; Betts et al. 1996b) and have tried nudging of soil moisture using the difference between an analysis of 2-m mixing ratio and short-term forecasts to constrain this drift.

Several of the 2-day forecasts here show significantly lower evaporative fraction on the second day than the first, implying a short time constant for the impact of model soil moisture dry down on evapotranspiration. For the bucket model in OCT95, this is a direct consequence of the specified bucket soil moisture. For the FEB96 model, it appears to be a consequence of the partition between evapotranspiration, which draws water from both soil layers, and direct evaporation from the first soil layer. The vegetation fraction is specified seasonally in the FEB96 model, and at the FIFE site it only reaches 0.6 in midsummer. Consequently, the direct evaporation from about $40 \%$ of the model grid area, which is modeled using the Mahrt and Pan (1984) threshold method, rapidly depletes soil moisture in the first soil layer and evaporation falls significantly from the first to second forecast day. Using an updated climatology for vegetation fraction, in which the vegetation fraction at the FIFE site has a higher, more realistic value $(0.83)$, reduces this error in a 2-day forecast, as 
does changing the formula for the direct evaporation parameterization. Betts et al. (1996a) noted that the twolayer version of the similar soil model in the MRF model (which has a fixed 0.7 vegetation fraction) has a similar dry down behavior. Natural vegetation systems have a much larger time constant [a week or two during FIFE (Kim and Verma 1990) rather than a day or two]. The Eta Model is typically used as a 48-h forecast model, but it will benefit from a better specification of vegetation fraction and an improved direct evaporation model, since it is undesirable that evapotranspiration fall sharply on the second forecast day. Both the model changes we tested in section 6 will be included in the next operational version of the Eta Model. It is likely that data assimilation will also need more soil layers, since this must handle all timescales from diurnal to seasonal. Betts et al. (1996a), in their study of the NCEP global model, also concluded that more soil layers were probably needed to represent intermediate timescales of the order of a week.

The other differences between the OCT95 and FEB96 models involve changes to the surface and BL schemes. For the surface-layer coupling, integral similarity functions (Lobocki 1993) derived from the Mellor-Yamada 2.0 turbulence closure scheme have been replaced over land by the Paulson (1970) integral similarity functions, coupled to the new skin temperature, with the Zilitinkevich (1995) formulation of the roughness heights (Janjić 1996b,c; Chen et al. 1997). This new surface layer formulation appears to work well in the FEB96 model. We cannot assess in detail the OCT95 formulation, because the diagnosis of the 2-m data was in error (and unfortunately this error is also in the 2-m GIST and ESOP-95 data archives).

The revisions to the BL turbulence scheme, described in Janjić (1996a), have improved the coupling of the BL scheme to the surface at night. The BL has now a more realistic cooling at night near the surface. Some of our cases still have too stable a nocturnal BL (but this could, in part, be due to errors in the surface radiation budget at night), so greater coupling between the surface and atmosphere in stable conditions may be desirable. This remains an area of uncertainty as observational studies of the stable BL under weak winds typically underestimate the downward surface heat flux. One very unstable daytime case suggests that the transfer coefficients in the growing unstable BL need to be higher, although this problem is reduced with the shorter model timestep used in the current $48-\mathrm{km}$ resolution Eta Model. Both BL schemes underestimate BL-top entrainment, the overshoot process by which warm, dry air is mixed down into the growing mixed layer. Since this was apparently high over the FIFE site (Betts and Ball 1994, 1995), comparison with the FIFE data makes this model deficiency rather apparent. However, the impact of surface flux errors, associated with problems of soil moisture initialization, vegetation fraction, bare soil evaporation, and net radiative forcing, are here as important as entrainment errors.

In the area of radiation parameterizations the two versions of the Eta Model are the same, and this is an area where significant improvement is essential, because the surface radiation balance is so important over land, even in short-term forecast models. As in many other largescale forecast models and climate models (Cess et al. 1995; Ward 1995; Betts et al. 1993; Betts et al. 1996a), the incoming daytime radiation at the surface is too high. In the Eta Model version tested, at solar noon under clear skies, this error may be as large as $10 \%-15 \%$. Subsequent investigation showed that part of this bias (about 5\%-6\%) came from two errors in the shortwave radiation code: the ozone absorption had been switched off and a circular earth's orbit had been used. These errors were corrected in the next operational model version. The remaining high bias in the incoming solar must be due to insufficient atmospheric absorption, scattering, or reflection of the incoming shortwave radiation, and is probably some combination (which we cannot assess here) of inadequate radiation parameterizations, lack of aerosol absorption, and cloud underestimation. Consequently daytime surface temperatures are often too high in the FEB96 model. One case study here showed quite high incoming solar radiation, even as it was raining in the model, again suggesting the cloud parameterization needs improvement.

All of our case studies show low incoming longwave radiation, particularly important at night. The OCT95 model (with too warm a BL) has incoming LW about $20 \mathrm{~W} \mathrm{~m}^{-2}$ less than observed, while in the FEB96 model, the difference is $35 \mathrm{~W} \mathrm{~m}^{-2}$, on average, for our case studies. In the FEB96 model the low downwelling LW, coupled to the skin temperature model and the stable BL parameterization, often leads to a rather cool skin temperature at dawn. The reason for this LW radiation bias needs further study.

One encouraging result of this case study comparison was the behavior of the model BL during daytime rain. Unlike the interaction observed in the global MRF (Betts et al. 1996a), here the convection scheme, boundary layer, and surface schemes interact (despite too high an incoming solar flux) in such a way as to preserve a realistic diurnal cycle, by maintaining a shallow mixed BL. Although it could be argued on observational grounds that this mixed BL is too deep during rain; this is consistent with the surface fluxes, which are high during the rain because of the positive surface net radiation bias.

The improvement of the physics packages in largescale models is a slow, steady process. The land surface boundary condition is critical to the accurate modeling of the diurnal BL evolution and hence the onset of, for example, convective precipitation (Beljaars et al. 1996; Betts et al. 1996b). As models evolve, they need careful testing and retesting against observational datasets, and the FIFE time series has again proved useful in assessing 
here the interaction of the near-surface components of two versions of the Eta Model physics. Furthermore, as more full-time automated surface flux sites are installed across the United States and Europe, there is a clear need for their surface flux data to be transmitted in real time to the operational forecast centers for near realtime validation of the land surface components of forecast models.

The operational version of the Eta Model, implemented on 18 February 1997, incorporated a bundle of physics changes, including (among several other changes) the revised bare soil evaporation discussed in section 6 and a new satellite-derived vegetation climatology, as well as corrections for the two errors in the solar radiation scheme discussed in section $3 \mathrm{a}$.

Acknowledgments. Alan Betts acknowledges support from the National Science Foundation under Grant ATM-9505018, the National Oceanographic and Atmospheric Administration under Grant NA56GP0380, and NASA under Contract NAS5-32356 for the processing of the FIFE data. We are grateful to the reviewers for improving the manuscript.

\section{APPENDIX A}

\section{Error in Diagnostics of Near-Surface Temperature and Humidity in OCT95 Model}

The operational Eta Model used for the GCIP summer archives in 1994 (GIST) and 1995 (ESOP-95) and from 1 November 1995 until spring 1996 coupled the surface and BL using the Mellor-Yamada level-2 and -2.5 schemes discussed in Janjić $(1990,1994)$ and Lobocki (1993). However, the near-surface temperature and humidity at 2 and $10 \mathrm{~m}$ were not diagnosed in a manner consistent with the model formulation, and they should be ignored by users of the GIST and ESOP-95 archives. Figure A1 illustrates this for 5-6 June 1987, showing

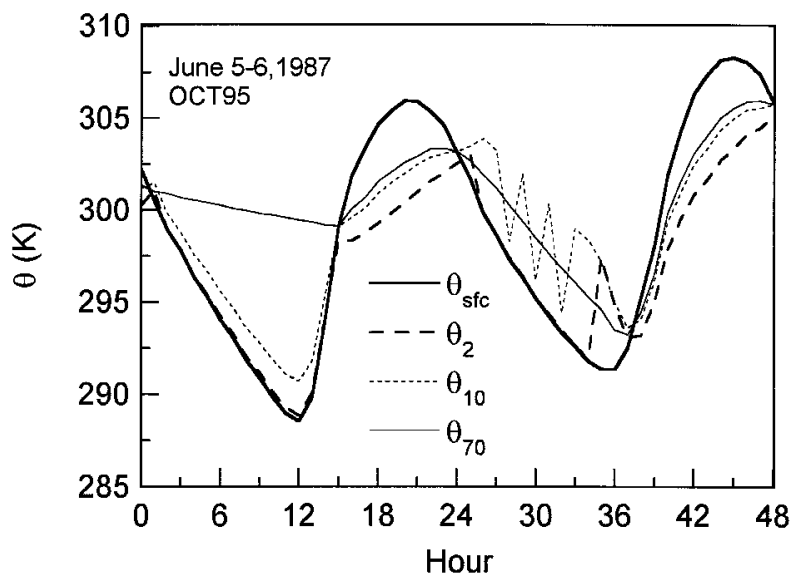

FIG. A1. The 48-h forecast from 0000 UTC June 5 with Eta OCT95 model showing $\theta$ predicted for surface and first model level (at about $70 \mathrm{~m}$ ) and diagnosed $\theta$ at 2 and $10 \mathrm{~m}$.

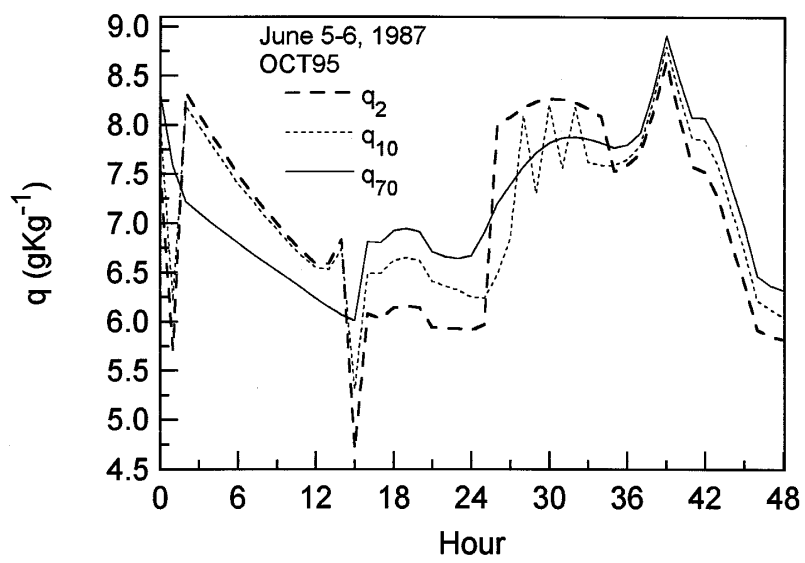

FIG. A2. As in Fig. A1 but for $q$ predicted at first model level and diagnosed at 2 and $10 \mathrm{~m}$.

potential temperature at four levels. The two levels predicted are shown solid. They are at the surface (calculated from the surface $T$, which is that of the first 10-cm soil layer), and the lowest model level (here about $70 \mathrm{~m}$ above the surface). It is clear that at the two diagnosed levels of 2 and $10 \mathrm{~m}$ (shown dashed and dotted), the values have been calculated incorrectly. They are noisy during the second night and do not lie between the two predicted potential temperatures in the daytime. Figure A2 shows the same problem for the mixing ratio at three levels; the lowest model level (predicted) and the two diagnosed levels. Note that this was not an error in the model equations that couple surface and BL, but an error in the method used to diagnose the 2 - and $10-\mathrm{m}$ variables from the model predicted variables.

In contrast, the FEB96 scheme, which has become operational (and now provides the GCIP Eta Model archive), has fixed this problem by using the Paulson scheme (see appendix B) consistently both to couple the BL scheme to the surface and diagnose near-surface variables. The corresponding near-surface profiles are now consistent (not shown).

\section{APPENDIX B}

\section{Summary of Eta Model Near-Surface Physics Parameterizations}

\section{a. The 1995 operational model (OCT95)}

\section{1) SOIL LAND-SURFACE MODEL}

The 1995 OCT95 model has a two-layer soil structure with a $0.1-\mathrm{m}$ first layer and a $1.9-\mathrm{m}$ second layer. A single soil type, a silty clay loam, is used with soil parameters specified from Clapp and Hornberger (1978). This is the same structure and properties used in the NCEP-NCAR global reanalysis. The soil hydrology uses Manabe's (1969) bucket model. The only prognostic variable in this model is the bucket water 
content $W$ (implicitly representing the available soil moisture for evaporation in the uppermost $1 \mathrm{~m}$ of soil) and is calculated from

$$
\frac{\partial W}{\partial t}=P-E-R
$$

where $P$ is the precipitation rate, $E$ the evaporation rate, and $R$ the runoff, which is produced only if the bucket is full. The bucket is allowed to evaporate at the potential rate $E_{p}$ if its content exceeds a critical value $W_{\text {crit }}$. Thus, the evaporation $E$ is

$$
\begin{aligned}
& E=\beta E_{p}, \\
& \beta= \begin{cases}1, & \text { if } W \geq W_{\text {crit }} \\
\frac{W}{W_{\text {crit }}}, & \text { otherwise. }\end{cases}
\end{aligned}
$$

In the OCT95 model, $W_{\text {crit }}=0.1125 \mathrm{~m}$ and $W$ was initialized for each forecast using a climatological value, which in the case of these runs was $W_{\text {crit }} / 10$. Thus the initial bucket water for these FIFE runs is about $11 \mathrm{~mm}$.

The soil thermal model is that of Nickerson and Smiley (Z. Janjić 1996, personal communication).

\section{2) BL AND SURFACE LAYER MODEL}

The 1995 OCT95 model is based on the physical package, outlined in Janjić (1990, 1994), Mesinger (1993), Lobocki (1993), and Gerrity et al. (1994). The surface layer of the OCT95 model is parameterized following the Monin-Obukhov similarity theory. This theory requires that boundary conditions be prescribed at two levels in the air. As usual, the values of the relevant variables at the lowest model level are used as the upper boundary conditions. Over open water surfaces, the values at the interface of an explicitly parameterized viscous sublayer (Janjić 1994) and the turbulent layer on top of it are used as the lower boundary conditions. The height of the viscous sublayer is different for different variables and depends on the flow regime. When a threshold value for friction velocity (or roughness Reynolds number) is exceeded, the viscous sublayer for momentum collapses. At a still higher threshold value, the viscous sublayer collapses completely, and the similarity theory is applied in the usual way, that is, using the values at the roughness height as the lower boundary condition. The integral similarity functions used over water (Lobocki 1993) were derived from the MellorYamada level-2 turbulence closure model (Mellor and Yamada 1982).

\section{b. The FEB96 model version}

\section{1) SoIL AND LAND SURFACE MODEL}

This also has a two-layer soil model with 0.1 - and 1.9-m thick layers, and it also has a distribution of soil type. The soil hydrology thermal model and vegetation package is that described in Chen et al. (1996). Soil parameters and seasonal vegetation parameters are specified at each grid point. The soil distribution, which includes nine soil types, is from the $1^{\circ} \times 1^{\circ}$ dataset of Zobler (1986), and the soil properties for each soil type are taken from Cosby et al. (1984). For initialization of soil moisture in the Eta Model, the values from the global reanalysis were empirically reduced for high volumetric soil moisture constants $(>0.26)$, because the global model appears to have a positive precipitation bias (K. Mitchell 1996, personal communication; Betts et al. 1996a). The formulas used are for each layer ( $i$ $=1,2)$ are

$\mathrm{SM}_{E i}= \begin{cases}\mathrm{SM}_{G i}, & \mathrm{SM}_{G i}<0.26 \\ \min \left(0.13+0.5 \mathrm{SM}_{G i}, 0.31\right), & \mathrm{SM}_{G i}>0.26\end{cases}$

where the indices $E$ and $G$ denote Eta and the global MRF model used for the reanalysis. An upper threshold of 0.31 is applied, as this is considered the field capacity of the soil in the global model.

\section{2) BL AND SURFACE LAYER MODEL}

The coupling of this new land surface scheme to the Eta Model led to some changes in the surface layer and roughness formulations. The radiative skin temperature is obtained diagnostically from the surface energy balance equation. In order to adapt the surface layer formulation in such a way as to use the radiative skin temperature as the lower boundary condition, instead of a near-surface air temperature, a viscous sublayer parameterization proposed by Zilitinkevitch (1995) was implemented. With this parameterization, the ratio of the roughness heights for temperature and momentum is a function of Reynolds number. The Beljaars (1995) correction is applied in order to avoid the singularity in the case of free convection with this correction: a fraction of the surface buoyancy flux is converted into the kinetic energy of unorganized flows near the surface so that the friction velocity, and therefore the Monin-Obukhov length remains nonzero. Also, for a technical reason, the Lobocki (1993) functions were replaced over land by those derived by Paulson (1970). Janjić (1996b,c) and Chen et al. (1997) outline these changes.

The FEB96 model also has some modifications to the Mellor-Yamada 2.5 formulation of the turbulent transports in the BL and free atmosphere; these are outlined in Janjić (1996a).

\section{REFERENCES}

Beljaars, A. C. M., 1995: The parameterization of surface fluxes in large-scale models under free convection. Quart. J. Roy. Meteor. Soc., 121, 255-270.

— P. Viterbo, M. J. Miller, and A. K. Betts, 1996: The anomalous rainfall over the United States during July 1993: Sensitivity to land surface parameterization. Mon. Wea. Rev., 124, 362-383.

Berbery, E. H., E. M. Rasmusson, and K. E. Mitchell, 1996: Studies 
of North American continental-scale hydrology using Eta model forecast products. J. Geophys. Res., 101, 7305-7321.

Betts, A. K., 1974: Reply to comment on the paper "Non-precipitating cumulus convection and its parameterization." Quart. J. Roy. Meteor. Soc., 100, 464-471.

— 1992: FIFE atmospheric boundary layer budget methods. $J$. Geophys. Res., 97, 18 523-18532.

— , and M. J. Miller, 1986: A new convective adjustment scheme. Part II: Single column tests using GATE-wave, BOMEX, ATEX, and Arctic Airmass data sets. Quart. J. Roy. Meteor. Soc., 112 693-710.

_ and J. H. Ball, 1994: Budget analysis of FIFE-1987 sonde data. J. Geophys. Res., 99, 3655-3666.

- , and - 1995: The FIFE surface diurnal cycle climate. $J$. Geophys. Res., 100, $25674-25693$.

— Geophys. Res., 101, 23 285-23 288.

— dataset 1987-89. J. Atmos. Sci., in press.

- - - and A. C. M. Beljaars, 1993: Comparison between the land surface response of the European Centre model and the FIFE-1987 data. Quart. J. Roy. Meteor. Soc., 119, 975-1001.

- S.-Y. Hong, and H.-L. Pan, 1996a: Comparison of NCEP/NCAR reanalysis with 1987 FIFE data. Mon. Wea. Rev., 124, 1480-1498.

, J. H. Ball, A. C. M. Beljaars, M. J. Miller, and P. Viterbo, 1996b: The land surface-atmosphere interaction: A review based on observational and global modeling perspectives. J. Geophys. Res., 101, 7209-7225.

Black, T. L., 1994: The new NMC Mesoscale Eta Model: Description and forecast examples. Wea. Forecasting, 9, 265-278.

—, J. H. Ward, and Z. I. Janjić, 1989: Tropical storm forecasts using Betts-Miller convection in NMC's Eta coordinate regional model. Research Activities in Atmospheric and Oceanic Modelling, WCRP 13, 5.38-5.39. [Available from World Meteorological Organization, Case Postale 2300, CH-1211 Geneva, Switzerland.]

Cess, R. D., and Coauthors, 1995: Absorption of solar radiation by clouds: Observations versus models. Science, 267, 496-499.

Chen, F., K. Mitchell, J. Schaake, Y. Xue, H.-L. Pan, V. Koren, Q. Duan, and A. Betts, 1996: Modeling of land-surface evaporation by four schemes and comparison with FIFE observations. $J$. Geophys. Res., 101, 7251-7268.

—, Z. I. Janjić, and K. Mitchell, 1997: Impact of atmospheric surface layer parameterization in the new land-surface scheme of the NCEP Mesoscale Eta Numerical Model. Bound.-Layer Meteor., in press.

Clapp, R. B., and G. M. Hornberger, 1978: Empirical equations for some soil hydraulic properties. Water Resour. Res., 14, 601604.

Cosby, B. J., G. M. Hornberger, R. B. Clapp, and T. R. Ginn, 1984: A statistical exploration of the relationships of soil moisture characteristics to the physical properties of soils. Water Resour. Res., 20, 682-690.

Gerrity, J. P., Jr., T. L. Black, and R. E. Treadon, 1994: The numerical solution of the Mellor-Yamada level-2.5 turbulent kinetic energy equation in the Eta model. Mon. Wea. Rev., 122, 1640-1646.

Gutman, G., and A. Ignatov, 1996: Derivation of green vegetation fraction from NOAA/AVHRR for use in numerical weather prediction models. [Available from NOAA/NESDIS, Office of Research and Applications, Washington, DC 20233.]

Janjić, Z. I., 1990: The step-mountain coordinate: Physical package. Mon. Wea. Rev., 118, 1429-1443.

_ 1994: The step-mountain eta coordinate model: Further developments of the convection, viscous sublayer, and turbulence closure schemes. Mon. Wea. Rev., 122, 927-945.

, 1996a: The Mellor-Yamada level 2.5 turbulence closure scheme in the NCEP Eta Model. Research Activities in Atmospheric and Oceanic Modeling, WMO, Geneva, CAS/JSC WGNE, 4.14-4.15. [Available from World Meteorological Organization, Case Postale 2300, CH-1211 Geneva, Switzerland.] 1996b: The surface layer parameterization in the NCEP Eta Model. Research Activities in Atmospheric and Oceanic Modeling, WMO, Geneva, CAS/JSC WGNE, 4.16-4.17. [Available from World Meteorological Organization, Case Postale 2300, CH-1211 Geneva, Switzerland.]

1996c: The surface layer in the NCEP Eta Model. Preprints, 11th Conf. on Numerical Weather Prediction, Norfolk, VA, Amer. Meteor. Soc., 354-356.

Kalnay, E., and Coauthors, 1996: The NCEP/NCAR 40-year reanalysis project. Bull. Amer. Meteor. Soc., 77, 437-471.

Kim, J. and S. B. Verma, 1990: Components of surface energy balance in a temperate grassland ecosystem. Bound.-Layer Meteor., 51, 401-417.

Lanzić, L., 1990: Forecasts of AMEX tropical cyclones with stepmountain model. Aust. Meteor. Mag., 38, 207-216.

_ 1993a: Eta model forecasts of tropical cyclones from Australian Monsoon Experiment: Dynamical adjustment of initial conditions. Meteor. Atmos. Phys., 52, 101-111.

_ $1993 \mathrm{~b}$ : Eta model forecasts of tropical cyclones from Australian Monsoon Experiment: The model sensitivity. Meteor. Atmos. Phys., 52, 113-127.

Leese, J. A., 1993: Implementation plan for the GEWEX ContinentalScale International Project (GCIP). Int. GEWEX Project Office 6, 148 pp. [Available from GPO, 1100 Wayne Ave, Suite 1225, Silver Springs, MD 20910.]

_ 1994: Major activities plan for 1995, 1996 and outlook for 1997 for the GCIP. IGP0 12, $166 \mathrm{pp}$. [Available from IGPO, 1100 Wayne Ave, Suite 1225, Silver Springs, MD 20910.]

Lobocki, L., 1993: A procedure for the derivation of surface-layer bulk relationships from simplified second-order closure models. J. Appl. Meteor., 32, 126-138.

Mahfouf, J. F., and J. Noilhan, 1991: Comparative study of various formulations of evaporation from bare soil using in situ data. $J$. Appl. Meteor., 30, 1354-1365.

Mahrt, L., and H.-L. Pan, 1984: A two layer model for soil hydrology. Bound.-Layer Meteor., 29, 1-20.

Manabe, S., 1969: Climate and the ocean circulation: I. The atmospheric circulation and the hydrology of the earth's surface. Mon. Wea. Rev., 97, 739-774.

Mellor, G. L., and T. Yamada, 1982: Development of a turbulence closure model for geophysical fluid problems. Rev. Geophys. Space Phys., 20, 851-875.

Mesinger, F., 1993: Sensitivity of the definition of a cold front to the parameterization of turbulent fluxes in the NMC's Eta model. Research Activities in Atmospheric and Oceanic Modeling 18, 4.25-4.38. [Available from World Meteorological Organization, Case Postale 2300, CH-1211 Geneva, Switzerland.]

1996: Improvements in quantitative precipitation forecasts with the Eta regional model at the U.S. National Centers for Environmental Prediction. The 48-km upgrade. Bull. Amer. Meteor. Soc., 77, 2637-2649.

- and T. L. Black, 1992: On the impact on forecast accuracy of the step mountain (Eta) vs. sigma coordinate. Meteor. Atmos. Phys., 50, 47-60.

- Z. I. Janjić, S. Nicković, D. Gavrilov, and D. G. Deaven, 1988: The step-mountain coordinate: Model description and performance for cases of Alpine lee cyclogenesis and for a case of an Appalechian redevelopment. Mon. Wea. Rev., 116, 1493-1518.

, T. L. Black, and M. E. Baldwin, 1997: Impact of resolution and of the eta coordinate on skill of the Eta Model precipitation forecasts. Numerical Methods in Atmospheric Modelling. The Andre J. Robert Memorial Volume, C. A. Lin, R. Laprise, and H. Ritchie, Eds., Canadian Meteorological and Oceanic Society, 399-423.

Pan, H. L., 1990: A simple parameterization scheme of evapotranspiration over land for the NMC medium-range forecast model. Mon. Wea. Rev., 118, 2500-2512.

, and L. Mahrt, 1987: Interaction between soil hydrology and boundary-layer development. Bound.-Layer Meteor., 38, 185202 . 
Paulson, C. A., 1970: The mathematical representation of wind speed and temperature profiles in the unstable atmospheric surface layer. J. Appl. Meteor., 9, 857-861.

Rogers, E., D. G. Deaven, and G. J. DiMego, 1995: The regional analysis system for the operational "early" eta model: Original $80-\mathrm{km}$ configuration and recent changes. Wea. Forecasting, 10, $810-825$.

Smith, E. A., W. L. Crosson, and B. D. Tanner, 1992a: Estimation of surface heat and moisture fluxes over a prairie grassland. 1: In situ energy budget measurements incorporating a cooled mirror dew point hygrometer. J. Geophys. Res., 97, 18 557-18 582.

— time-space variability over the FIFE experimental domain. $J$. Geophys. Res., 97, 18 599-18622.

Strebel, D. E., D. R. Landis, K. F. Huemmrich, and B. W. Meeson, 1994: Collected data of the First ISLSCP Field Experiment. Surface Observations and Nonimage Data Sets, Vol. 1, NASA Goddard Space Flight Center, CD-ROM.

Sugita, M., and W. Brutsaert, 1990a: Wind velocity measurements in the neutral boundary layer above hilly prairie. J. Geophys. Res., 95, 7617-7624.

, and $-1990 \mathrm{~b}$ : How similar are temperature and humidity profiles in the unstable boundary layer? J. Appl. Meteor., 29, 489-497.

Viterbo, P., and A. C. M. Beljaars, 1995: A new land surface parameterization scheme in the ECMWF model and its validation. $J$. Climate, 8, 2716-2748.

Ward, D. M., 1995: Comparison of the surface solar radiation budget derived from satellite data with that simulated by the NCAR CCM2. J. Climate, 8, 2824-2842.

Zilitinkevich, S. S., 1995: Non-local turbulent transport: Pollution dispersion aspects of coherent structure of convective flows. Air Pollution III, H. Power, N. Moussiopoulos, and C. A. Brebbia, Eds., Air Pollution Theory and Simulation, Vol. 1, Computational Mechanics Publications, 53-60.

Zobler, L., 1986: A world soil file for global climate modeling. NASA Tech. Memo. 87802, 33 pp. [Available from NASA Goddard Space Flight Center, Institute for Space Studies, 2800 Broadway, New York, NY 10025.] 